\title{
Merging Balanced Scorecards and Business Intelligence Techniques: An Applied case on the IT Subsidiary Company in the Egyptian Civil Aviation
}

\author{
Ayman E.Khedr \\ Assoc. Prof., Information system \\ department \\ Helwan University \\ Cairo, Egypt
}

\author{
Manal A. Abdel-Fattah, PhD \\ Ass. Information Systems \\ Department \\ Faculty of Computers and \\ Information \\ Helwan University
}

\author{
Marwa M.Solayman \\ Information system department \\ Helwan University \\ Cairo, Egypt
}

\begin{abstract}
A very important challenge for organizations is to have an integrated measurement framework that effectively defines the performance measures and connect them with the organizations' strategies, then to analyze and report the results efficiently. Here comes the role of the Business Intelligence (BI) as an essential key factor that presents and translates the measurement results, for the performance measurement is one of the BI techniques. This paper focuses on adopting the Balanced Scorecard (BSC) as a key framework for performance measurement to manage and measure the organizations' businesses. Merging both BI and BSC approaches gives a very strong roadmap to identify strategic goals, measures and take the right actions according to the measurement results. In this paper, the BSC model was applied along with some BI tools such as dashboards, analytical charts and performance measures on the IT arm for the civil aviation in Egypt to define clear connections between strategic objectives, the business processes by which the strategies are executed, and the Key Performance Indicators (KPIs) that measure business performance. Moreover, the current system was fully evaluated, and suggested corrective actions were reported to the strategic management, and a quick look is provided for how the BSC results can be presented using the BI techniques.
\end{abstract}

\section{General Terms}

BI Tools, SPM, Performance measurement results interpretation, performance patterns.

\section{Keywords}

Business Intelligence; Strategic Performance; Balanced scorecard; Performance measurement; KPI Dashboards, Strategic Objectives.

\section{INTRODUCTION}

"How can we best measure the strategic performance by defining the most indicative performance indicators and translate strategies into action, applying the BI's most appropriate tools in the performance measurement process?" In short, this is the central question addressed in this paper.

All leading organizations look for new innovative methods that would increase revenue, improve performance and create better relationships with their clients. [23] Such results can be accomplished through using Business intelligence (BI), for it supports decision making at every level, enables all staff members to act effectively upon any given situation. BI tools facilitate defining the appropriate strategies as well as associating them with the right performance measurement frameworks.

In performance measurement, using BI tools has become crucial in order to extract, integrate and report the organizations' performance measurements metrics. Thus they enable decision makers to take corrective actions, adopt new management initiatives and new strategies. The key BI approaches are the performance management and dashboard, and this paper mainly focuses on adopting the Balanced Scorecard (BSC) as a performance management and measurement tool that represent data effectively by aligning BI with the applied BSC model.

Not only does Performance measurement provide a clear picture of the organization's progress in accomplishing its goals. But also it offers a different learning culture among the entire staff in decision making, and helps realizing improvement opportunities for the organization, and finally accelerates the organization's progress and targets accomplishments. [16] Performance measurement framework works in methodical steps; it defines metrics, collects and analyzes data, then rearranges them to take improvement and corrective actions. This paper focuses on representing results with the BI tools, thus, it uses BSC framework to focus on all perspectives rather than just the financial perspective in order to achieve balance in performance measurement.

As one of the main components used in Performance Management, BI is a technology-driven process used to analyze data to help both corporate staff and end users take more informed business decisions. With its various tools, applications and methodologies, BI helps organizations collect data from internal systems and external sources, prepare it for analysis, develop and run queries against the data. As one of the main components used in Performance Management, BI is a technology-driven process used to analyze data to help both corporate staff and end users take more informed business decisions. With its various tools, applications and methodologies, BI helps organizations collecting data, preparing its analysis, creating visual demos and reports to finally receive analytical results that would help both the organization decision makers and operational staff. Among the benefits of BI systems is help organizations identify market trends and recognize problems. Furthermore, it enhances the decision making capability, enhances internal 
processes, optimizes operational efficiency, adds new revenue sources, and obtains advantages over business competitors.

BI data analysis supports both strategic and tactical decisionmaking processes. Initially, BI tools were primarily used by data analysts and other IT professionals who ran analyses and produced reports with query results for business users. Increasingly, however, business executives and workers are using BI tools, and reports to discover results and re-define the data inputs.

Additionally, BI technology comprises visualized data tools that can create charts and graphical data presentations, and uses tools that can build BI dashboards and performance scorecards to show business metrics and key performance indicators data in an easy visual way, and thus, enable decision makers and strategic management quickly understand how the performance of the organization's processes and operations going through these visual outputs. [11]

Over the past decade, BSC has been increasingly implemented by more companies as a key framework to manage their businesses. On top of being an effective communication tool of key strategies, the BSC provides clear connection between strategies, the business processes executed by strategies, and the Key Performance Indicators (KPIs) that measure business performance. [1]

From a performance management perspective, BSC provides the baseline for performance measurement, and based on industry research, many companies that use the BSC are satisfied with the method and plan to keep on using it. Therefore, it cannot be denied that it is valuable to be able to measure performance from financial, customer, operational, and learning perspectives. [1]

\section{RELATION BETWEEN BI AND BSC}

"If companies align balanced scorecards and business intelligence they can achieve a performance management system that delivers superior results." [1].

As one of the business performance management (BPM) frameworks, BSC has been adopted by many major organizations over the past decade. A 1999 Bain \& Company survey regarding management tools adoption showed that $44 \%$ of surveyed organizations used BSC with a satisfaction score of 3.85, with 5 being the highest. Although other management tools scored higher adoption and satisfaction rates, BSC will be considered the key BPM framework tool within organizations in the near future to improve business results. [1]

Strategic Performance Measurement means to make a business successful as the budget process. Just as with setting short-term direction for the company with a budget, management is responsible for setting long-term strategic direction and goals for the company. Some instances for strategic management activities are choosing which markets does the company target? What are the requirements for the market competition? Which products or services to be offered for clients, and why? How to achieve and sustain a competitive advantage using these products and services? How to train employees effectively to handle customers' needs? What are the most critical internal processes that need improvement to cut cost or increase the service level?

Simply put, using Strategic Performance Measurement keeps the organization focused on goals and activities that would make a difference in the near future. Since the lead-lag relationship among strategic activities is immense, it is critical to make decisions regarding the organization's direction that would lead for its long-term success.

It is even more important to ensure achieving strategic success drivers, thus, Strategic Performance Measurement sets both managers and employees to focus on their day-to-day jobs, since they should be aware of how they play a big role in strategic activities. [8]

After defining all strategic objectives, KPIs and initiatives, and connecting them with the target values upon which they are measured, it is very important to present the measurements results.

For a better understanding and analysis of business parts and measurement results, it is tended to use BI techniques to define BSC parts and represent its results, which eventually defines the necessary actions to be taken.

To provide business strategies with the correct directions, it is vital to show the BSC structure in a clear, comprehensible way. Therefore, BI is used not only to present the BSC structure, but also the output values using graphical demonstrations, such as charts, dashboards, strategy maps showing cascading relations among objectives. These output values are stored in a knowledgebase, and data mining techniques can be used for future analysis. BSC data connections among perspectives, objectives, KPIs, initiatives and actions - can be presented through different delivery channels like Excel formatted KPIs, Mobile and Desktop applications, and Web based solutions.

Using BI solution as a tool for supporting corporate strategy, can improve how performance management programs work to elevate the organization's value. Businesses that seek BSC strategy would use BI solutions for trend analysis, predictive analysis, customer data integration, scorecards and dashboards, and data mining. Studies have proven that it is the most successful performance management methodology to present a measure and follow using BSC and strategy maps, then select metrics based on strategic objectives set, and then finally deploy BS solutions to collect the necessary data for performance optimization.

The obstacle facing many organizations is that they operate in reverse. They use the easily collected information to determine how to manage their business and strategies. Rather, what these organizations should do is deciding what are their strategies and then align the available information to support these strategies. [4]

The BI BSC is designed in a manner that makes results easy to understand and use. What makes it unique is its ability to assess how the BI system of an organization competes with the best in the field. It allows creating IT standards, defines what type of data is needed for the business, and evaluates the organization's BI history.

To make strategic performance results more readable and help decision makers take consistent trends to achieve their targets, BI helps providing trend analysis, predictive analytics, integrated customer views, scorecards and dashboards.

As seen below in Table 1, an illustrated comparison between the BSC and BI as management tools. 
Table 1. Comparison of Balanced Scorecard and Business Intelligence as Management Tools Source: [1]

\begin{tabular}{|c|c|c|}
\hline Points of Comparison & Balanced Scorecard & Business Intelligence (BI) \\
\hline $\begin{array}{c}\text { Vintage and } \\
\text { Central Objectives }\end{array}$ & $\begin{array}{l}\text { Circa 1996. Communicate business strategies and } \\
\text { align organization. Manage strategy execution. } \\
\text { Measure organizational performance. Align goals, } \\
\text { compensation, skills, resources, budgets, and plans. }\end{array}$ & $\begin{array}{l}\text { Circa 1994. Leverage business information, } \\
\text { analytical tools, and decision support techniques } \\
\text { to enhance core business processes that improve } \\
\text { business performance and profits. }\end{array}$ \\
\hline Organizational Scope & $\begin{array}{l}\text { Mainly enterprise, with cascading performance } \\
\text { measures to SBUs, divisions, departments, and so } \\
\text { forth. Can be applied at SBU and lower levels } \\
\text { independently of whether or not there is a higher-level. }\end{array}$ & $\begin{array}{l}\text { Enterprise, SBU, division, function, departments, } \\
\text { and so forth. Can be - and often is - applied at } \\
\text { any of these organizational levels independently, } \\
\text { though that may not be ideal. }\end{array}$ \\
\hline Customer Focus & $\begin{array}{l}\text { Mainly internal for all levels of executives, managers, } \\
\text { and analysts. }\end{array}$ & $\begin{array}{l}\text { Mainly internal for all levels of executives, } \\
\text { managers, and analysts. Can also be used to boost } \\
\text { product and/or service offerings to external } \\
\text { customers. }\end{array}$ \\
\hline $\begin{array}{l}\text { Key Management } \\
\text { Linkages }\end{array}$ & $\begin{array}{l}\text { Links business strategies to key business processes } \\
\text { and initiatives that drive strategy execution and } \\
\text { business performance. Links strategies to goals, } \\
\text { compensation, skill development, resources, budgets, } \\
\text { and plans. }\end{array}$ & $\begin{array}{l}\text { Links business strategies, core business processes } \\
\text { and initiatives, and business information, } \\
\text { analytical tools, and decision support techniques } \\
\text { that can be used to improve those core business } \\
\text { processes and achieve strategic goals. }\end{array}$ \\
\hline $\begin{array}{l}\text { Information Strategy } \\
\text { and Focus }\end{array}$ & $\begin{array}{l}\text { Primarily ad hoc, manual reporting of performance } \\
\text { measures from financial, customer, operational, and } \\
\text { learning perspectives. Some multi-dimensional } \\
\text { analysis using BI tools, often using stove-piped } \\
\text { approach to data acquisition }\end{array}$ & $\begin{array}{l}\text { Integrate multi-dimensional business information } \\
\text { to support use of wide range of automated } \\
\text { analytical tools and decision support techniques } \\
\text { to improve the efficiency of core business } \\
\text { processes that drive business results. }\end{array}$ \\
\hline $\begin{array}{c}\text { Performance } \\
\text { Management Focus }\end{array}$ & $\begin{array}{l}\text { Measure performance of strategically important } \\
\text { business processes and take action to improve as } \\
\text { required. Use performance measures to guide strategic } \\
\text { investments and plans. }\end{array}$ & $\begin{array}{l}\text { Use well-managed enterprise business } \\
\text { information, automated analytical tools, and } \\
\text { modern decision support techniques to manage } \\
\text { and enhance core business processes that control } \\
\text { overall business performance and profitability. }\end{array}$ \\
\hline
\end{tabular}

As illustrated in the above table, there are common focus points between BSC and BI. While the BSC is crucial to measure and present the strategy, the $\mathrm{BI}$, on the other hand, is necessary to interpret the measurement results.

Although BSC deals with business performance, but BI mainly generates data-driven insights on business performance. Even though both BI and BSC work in the same field, yet there is very little information on integrating one of them into the other. Generally, BI is represented by set of process steps, they are as follows:

1. Collecting data.

2. Using analysis tools to process the data.

3. Making decisions based on data insights.

Next, collected data should be properly converted into a data source for the KPIs of the BSC. Consequently, BI data insights might be used for action plans aligned to the BSC KPIs. Normally BI is what helps to generate actionable KPIs.

\subsection{Integration between classical BI and classical BSC}

$\mathrm{BSC}$ and BI interconnection can be summarized as follows:

- BSC focuses BI data collection and analytic on what matters by providing strategic objectives.
- BI feeds KPIs of Balanced Scorecard with insightful data.

- $\quad$ BI can be a source for action plans aligned with strategic goals and KPIs.

- $\quad$ BSC-BI integration is recommended when there is a base for a solid business-centric BI architecture.

- $\quad$ BSC is used in the BI architectures as a valuable ad-on to explore more business opportunities since BSC's focus is to collect the data that matters and categorize it according to its connections.

As presented in figure 1, there is a common set of correlation between BI and BSC, BSC is providing the necessary basement represented in the data collection, strategic objectives alignment, and KPIs as this alignment will be translated and interpreted by the BI tools in performance measurement output and action plans.

Presenting Strategies and measuring the performance using the $\mathrm{BI}$ is an essential part in the performance output translation; in order to use the BI in an efficient presentation and consolidation of the performance measurement; major steps are followed in order to prepare for the performance measurement presentation by $\mathrm{BI}$, this involves data collection, data consolidation and internal and external reporting. 


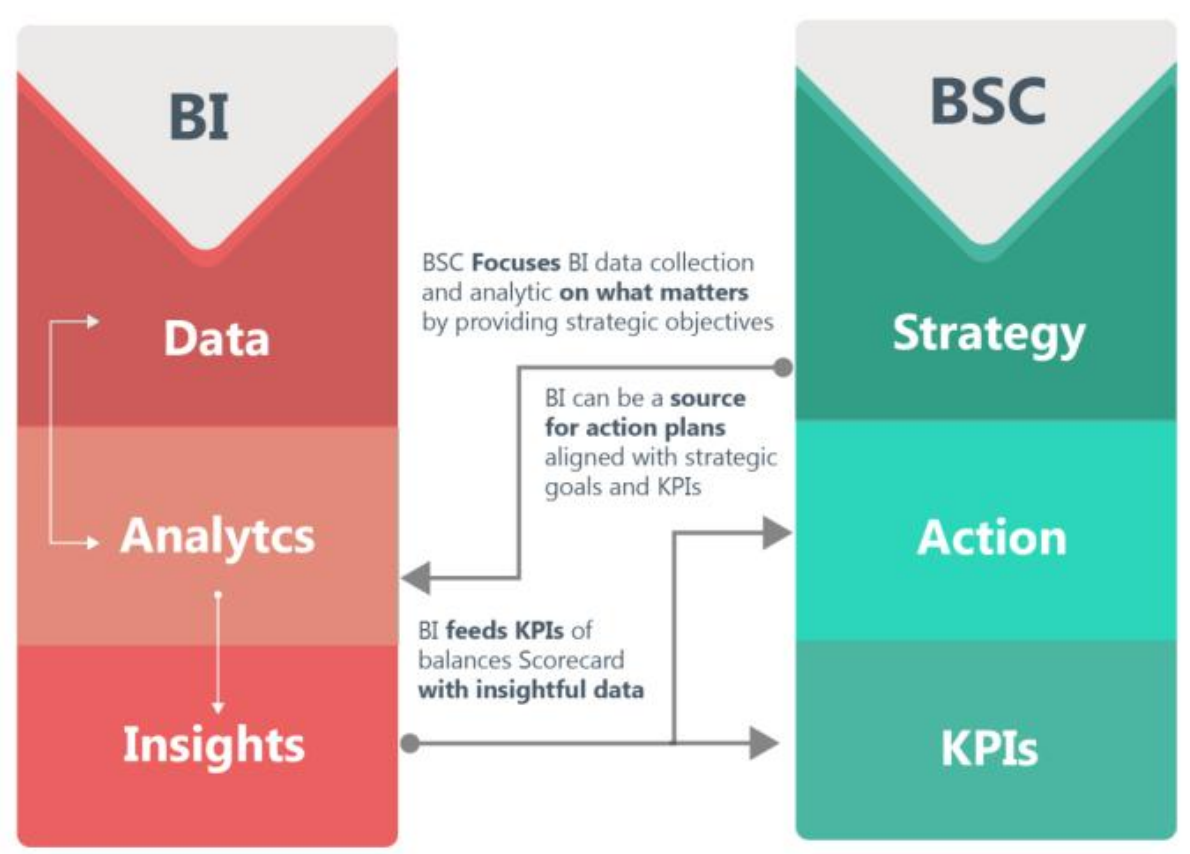

Fig 1: Integrating BSC with Business Intelligence [17]

The first step to understand $\mathrm{BI}$ is to understand the BSC as a performance management methodology. BSC is a performance management tool, while BI is a tool that examines strategy and manages performance as well. [9] The reason why for involving performance management is because BI provides the data that helps organizations create plans to improve / update their processes, and finally achieve the required results.

The main target is to create a detailed vision for defining the organization's strategic goals and objectives, and setting measures for these objectives. This paper focuses on the BSC as an applied BI tool and a measurement framework to help an organization associate its vision to its strategies in order to achieve current goals and enhance its plans according to the performance measurement results. This is achieved through creating strategic objectives, key performance indicators, management initiatives and actions to lead the business performance measurement.

Further target is to automate BSC reports using new defined techniques and BI dashboards to deliver a full performance analysis, integrated customer views and dashboards. Also, to create a consistent framework to monitor the organization's performance trends and define the most appropriate required actions. [2]

A final important target is to represent strategic performance results. Thus, it is an essential part in this paper to adopt BI in representing these results, since BI systems are known to be responsible for transforming data into information, and they create a healthier environment in organizations for effective decision making as well as strategic thinking. [10]

\section{CASE STUDY SETUP}

Here is the chronological order for adopting the BSC framework setup. After a short preface to the study design and methods, a general discussion of the synopsis case of the performance measurement process, which is applied on the civil aviation IT arm, is described, with throwing lights on the intended impact of applying the BI-based performance indicators The Description of the Civil Aviation, case unit: Civil Aviation IT Company, this section is about the BSC implementation steps on one of the Egyptian Civil Aviation companies, which represents the technology arm for the Egyptian ministry of civil aviation. The reasons for selecting this company as the candidate enterprise for applying the strategic performance evaluation will be presented in details. Also, the steps followed to implement the BSC will be detailed.

\subsection{The design and methods of data gathering}

Simply, a research design is the framework for a study, as it gives the wide guidelines to walk one through in data collection and analysis. Depending on the research nature, many research design frameworks can be found. For example, descriptive research designs are used to determine the relationship among the variables, while exploratory research is used to understand the challenging problem in the research, provide insights into it, and form specific hypotheses. [21]

Both exploratory and descriptive research contribute to theory development, however, seeking such development is definitely present in causal research. (Saunders et al., 2000) Nevertheless, the theoretical development in the multiple constituency approach is considered imprecise in making this study part of a testing research, and therefore, the basic form of this research study is both descriptive and explanatory.

In this paper, a mixed method approach has been adopted where both techniques - exploratory and descriptive - are used. Known as the 'triangular' research design, it improves the data quality, and thus, the precision of the findings, leading to a better understanding or questions that can be answered in later researches. [21] 


\subsubsection{Data gathering methods}

Data collection methods are generally based on the research design, research questions, and other different issues. Owing to specific technical and practical problems in each of these methods, the survey and empirical evidence for this part of study is collected at different organizational levels and through various methods, such as semi-structured personal interviews (face-to-face interviews with a well-prepared questionnaire, reviews of presentations, process documentations, and direct observations).

Using the triangular technique enables researchers to see the issue under study from several perspectives and also allows validating both existing and emerging concepts. (Khedr, 2008) For a six-month field visit in 2014, the researchers interviewed the heads of departments, QA manager, project managers, operations managers and department members. The visit was to observe the adoption processes and interaction effects among the context elements of uncertainty factors. The triangular interview was able to observe behavior / processes steps through the constant access to corporate documentation.

\subsection{Case Overview}

Civil aviation in Egypt is a very important sector where large sets of knowledge, operations, processes and data are being executed, and the focus of applying strategic performance measurement was one of the major subsidiaries in the civil aviation sector. The company under focus was the IT arm of the civil aviation. Being a study subject, the subsidiary company was a target to start applying a full assessment for its vision, mission, processes, performance measurements and management initiatives procedures.

Sequential steps were followed to implement the strategic performance measurement using the BSC and its applied case study. The first step of applying a BI-BSC framework was to draw the management attention to the importance of having a consistent framework that aligns the strategic goals and objectives with the performance management in order to best achieve the intended targets and spot the strength and weakness points. Thus, presentation sessions were held to strategic management and board members to have a mature understanding level and a majority agreement for the emerging need to apply a strategic performance measurement system in the civil aviation, taking the information technology subsidiary company as a starting point from which a success story will result in applying the performance measurement on all the Civil Aviation companies.

The Motivation of using BSC as a performance measurement framework was communicated to the top management in the Civil Aviation was focusing on specific points:

From a performance management perspective, the BSC provides the baseline for performance measurement, and according to industry research, many companies are satisfied with their BSC method and plan to continue its use. Therefore, it cannot be denied that the way of measuring performance from financial, customers, operational, and learning perspectives is valuable.

The BSC is a strategy performance management tool - a semistandard structured report, supported by design methods and automation tools that can managers can use to track and monitor their staff's activities accomplishments.

In the 2010 Annual survey of management tools by Bain \& Company, it was reported that BSC, probably the best known of several frameworks, was the most used performance management framework. It was originated in the early 1990s. Later on, the BSC has evolved to become an effective strategy execution framework.

Seeing it as a critical foundation in a holistic strategy execution process, the BSC helps organizations formulate strategy and turn it into actionable terms. Moreover, it provides a road map for executing this strategy to continually align it with all the organization's staff. The BSC helps leaders to move from reactive decision mode to proactive mode.

Given that the main value of BSC is the balance itself, the BSC does not focus on one performance area; it allows business managers to view all perspectives of a business rather than just the financial measures. BSC draws attention to customers, employees, internal processes and the growth and potential strengths for the organization.

A good BSC framework provides an insight vision for how the organization should handle its processes and get results. To sum up, the BSC can be seen as:

- A multi focused framework,

- A goals achievement measurement tool,

- A motivation and rewarding system,

- An intellectual capital performance tool,

- A benchmarking tool,

- A linking tool connecting business processes and objectives with strategic perspectives and objective.

Onset meetings were held with the top management to give them an initial view about the impact of applying the performance management/measurement system on the Civil Aviation companies. Generally, the proposed model discussed with the Civil Aviation management was promoted to focus on:

1. Measuring organizational, business unit or departments success, thus, balancing both long and short term actions.

2. Identifying the diverse measures of success from different business perspectives that are: financial, customers, internal operations, human resource systems and development, learning and growth perspectives.

3. Using the BSC as the way of connecting the strategic objectives and their related measures to actions.

4. Providing consistent, clear yet accurate reporting for the performance measurement results to the top management that aims to help them in the decision making.

One of the main questions that were asked was: Why we should adapt the BSC model? So, the purpose of using the BSC was discussed. Hence, the following points are to sum up what the proposed Civil Aviation IT company strategic performance model aims to:

1. Defining the Civil Aviation business processes and activities.

2. Providing simple, accurate and consistent definitions of Civil Aviation vision, mission, values, and goals.

3. Identifying the key strategic objectives all over the Civil Aviation as an organization and the main objectives and targets for each department.

4. Building a consistent well defined strategy map for the strategic objectives with clear cause and effect relations between them, and communicating the strategy map to the top management to take their initiatives regarding the defined strategic objectives and their relations. 
5. Identifying the measurements or the KPIs that are considered the basic elements to define the targets to be achieved, the performance current status, and the actions and management initiatives required from the management in order to achieve the strategic objectives

In order to have a consistent view of the current and future strategy, all the above key elements for the case unit SPM must be aligned together and well defined. Company's mission, vision, values, current status, success stories, long term strategies, plans and goals were required to be documented, and then the BSC framework is implemented to measure the Civil Aviation strategic performance, Figure 2 shows a description of the steps to create a BSC with all its components mapped together. Each perspective may have one or more objective, then for each objective there is a set of identified measures, and the main property that will be a reference measurement value is target value assigned for each KPI.
Many current performance measurements system use some variant of the BSC. An illustration is made for the selected subsidiary company for the SPM project. The basic BSC components are defined and appropriately connected before moving forward in the measurement process. Successful definition of strategic objectives, KPIs and targets is the key to have both complete and accurate performance system. The main objective then from having the main BSC elements connected together is the key for a successful future planning. A successful performance measurement system must be able to identify opportunities and problems rapidly, allocate resources after stating priorities, track any strategy change, define responsibilities and reward accomplishments, improve processes, and promptly generate plan and prediction. [14] The first step for an appropriate performance measurement is aligning BSC components and mapping them accurately as presented in figure 2

\section{BSC Framework}

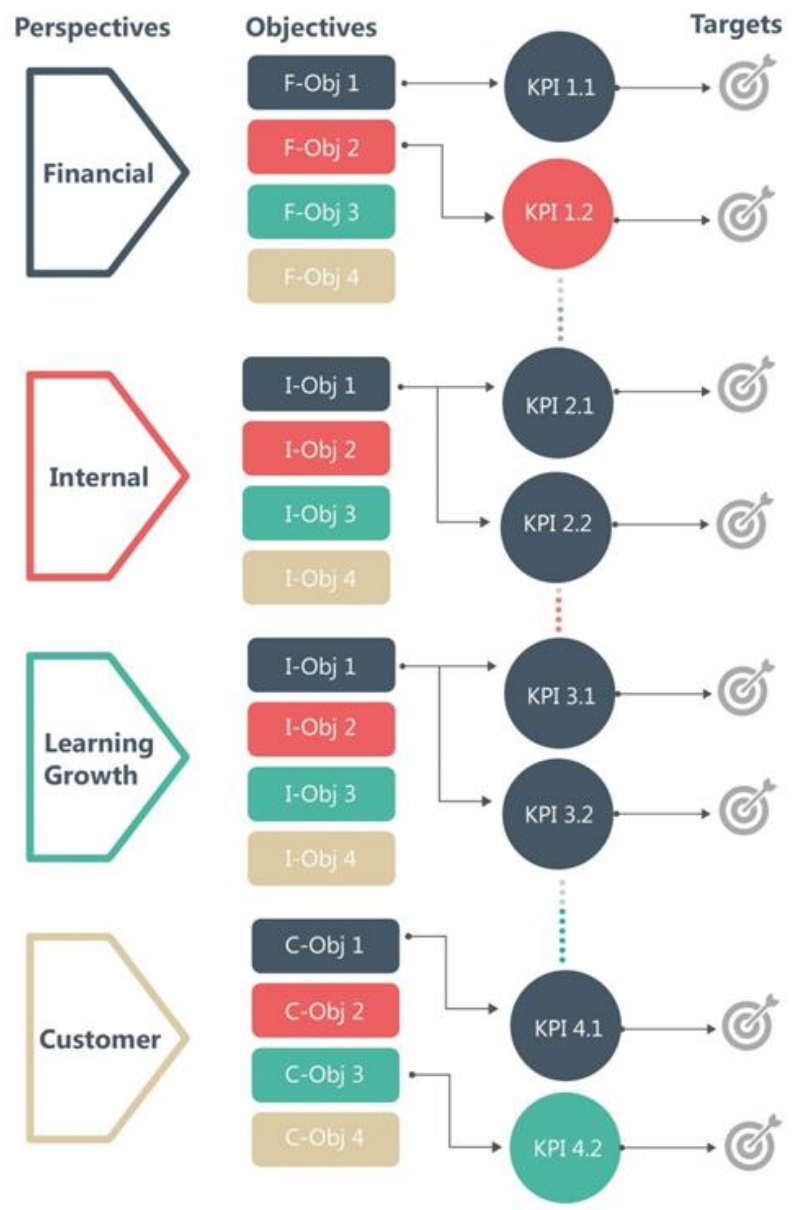

Fig 2: BSC Framework [5]

\subsection{Case unit}

The candidate company is a subsidiary of the Egyptian Holding Company for Airports and Air Navigation (EHCAAN), affiliated to the Egyptian Ministry of Civil Aviation

This subsidiary company has been established since November 2002 under the Egyptian law 203 for the year 1991 to provide ICT products, services and solutions that are customized to serve the Civil Aviation in Egypt. Moreover, the company contributed in major and critical projects for governmental entities as well as major private companies. It succeeded to acquire a huge customer base of more than 70 Clients and over 200 contracted projects. 


\subsection{Motivation and criteria of choosing the case unit (civil aviation IT Services Company)}

Before deciding to use the scorecards and dashboards in or even enforcing a performance measurement framework, there are some criteria and elements should be considered when choosing the organization's units for which the BSC is implemented, such elements contribute to the selection of an appropriate organization unit. [9]

1. Strategy: BSC is a methodology designed to help transforming the strategy into objectives and measures, so the most important criterion is whether the unit has a coherent strategy.

2. Sponsorship: It is vital that the executives sponsor the performance measurement and BSC concept, they have to see the need for having a measurement system, if the leaders are not aligned with the BSC goals and objectives, and they don't believe in the BSC metrics and needs, then the efforts to build it will be severely compromised.

3. The need for BSC: This must be cleared, and the main question that identifies this need is that whether the business unit needs to revamp its performance measurement system or not. There are seven signs that can indicate that a new system is needed.

4. Support of key managers and supervisors: It is for sure that executive support is critically required to implement a BSC. Yet, while executives may use BSC data to make strategic decisions, top management will have to use the tool in their jobs. When the BSC is cascaded to all management levels, the alignment and focus derived across the organization can lead to a real performance development.

5. Organizational Scope: The selected unit should have a strategy, defined customers, specific processes, operations and administrations. This wide function focus enables the BSC to cover all performance aspects, and thus, affect the overall performance.

6. Data: This includes supporting the measurement culture in the organization, and enabling all data to be visible and chosen by the BSC. In addition, new data sources have to be communicated to the BSC context as well to be used if they are potential measurement sources.

7. Resources: A measurement system can't be built by individuals efforts, the best BSCs are created through team efforts that are committed to a common management goal.

The chosen unit should be able to supply resources for the implementation. In the selected case unit, there is a defined strategy for the whole organization, although it was needed to define a new strategy, new objectives and targets for the IT arm in the Egyptian civil aviation, but at least a strategy is defined. The support from the executives after cycles of consistent meetings and discussions additionally focal points had been addressed to be the change champions for the BSC implementation.

The organizational scope is wide in the case unit, for in the IT services company, there are customer base, training department, marketing department, project management processes, quality assurance processes and a variety of functions that are considered a rich environment for applying the BSC and translating the measurement results in a BI reporting dashboards.

Performance is acceptable on all dimensions except profit. A focus on quality and other measures has led to improvements in isolated areas but not in profits

Customers don't buy even when the prices are competitive. The problem may lie in the benchmarking to the competitors

Business unit needs to revamp its performance measurement system: the objectives from having a performance measurement system are clear and accurately defined

Managers spend significant time debating in the meaning of the measurements; this means that the measures are not clearly linked to the strategic objectives.

Share price is lethargic despite solid financial performance. No long term value creating activities.

Performance measures haven't been changes in a long time. Performance measures should be dynamic based on the organization's strategic direction

The corporate strategy is changed recently, since all measures should be linked back to the strategy, any change in the strategy is reflected on the measurements

Fig 3: Signs for the need of performance measurement revamping [9] 
Being the Civil Aviation technology arm, this candidate company has technology core competencies which are lying in:

- Full solution Provider: System Integration, and consultation center.

- Reliability: Having a Solid Financial Foundation.

- Trustability: A governmental entity under the supervision of the Civil Aviation Ministry.

- Profound knowledge in understanding the Aviation Sector's unique requirements.

- A Lead provider of technical support \& SLAs.

- A Complete services' portfolio provider

Each one of the above competencies is by itself a motivation point to start a complete strategic measurement system and evaluate to which degree these competencies are taken into consideration in the AVIT strategic objectives, processes, evaluation systems.

AVIT is a rich environment for applying a performance measurement framework lead by a BSC and BI dashboards implementations, the company's scope of work, the clients base, the projects base are main factors of choosing it as this paper's case unit.

- Build, operate and maintain an IT Network Infrastructure in the civil aviation sector.

- Standardize and apply core supporting business applications needed mainly for the civil aviation sector.

- Provide consulting services for Organization restructuring process, Operations Control Center, Crisis $\&$ Security Center.

\subsection{The required input data sets and resources}

1. Proper strategic management points of contacts to identify the current situation, processes and the overall objectives to be achieved for Civil Aviation.

2. Reliable references to describe the main key processes and activities involved in Civil Aviation.

3. Main key departments for which the performance must be identified and that their overall performance affects both current and planned objectives achievement.

4. Full details on the current reporting system, who is reporting and what is being reported, how are they identified and structured and whether they are useful.

5. The currently followed performance evaluation system and measurements for both personnel and organizational performance.

\subsection{The output of applying the SPM using BSC for the implemented case}

1. Full assessment for the current organization structure, strategies, services and projects evaluation and internal processes.

2. Full strategic performance model with all the objectives, KPIs and strategy map defined.

3. Set of corrective actions, and recommendation for performance enhancement.

4. Consistent periodical performance report for the top management

5. Predictive and trend analysis for the upcoming plans and strategies

\subsection{Adopted BSC building steps}

There are nine core steps followed to build a BSC. These steps were followed in implementing the BSC for the Information technology services civil aviation subsidiary (as illustrated in figure 4).

The award-winning framework, "Nine Steps to Success" is considered a practical approach to create a strategic planning and management system based on the BSC. Using a disciplined framework provides an organization with a method to connect the different components of strategic planning, management and measurement, and it commits a visible connection between the projects and programs on which people are working, the measurements used to track success, the required strategic objectives, and the mission, vision and strategy of the organization. [18]

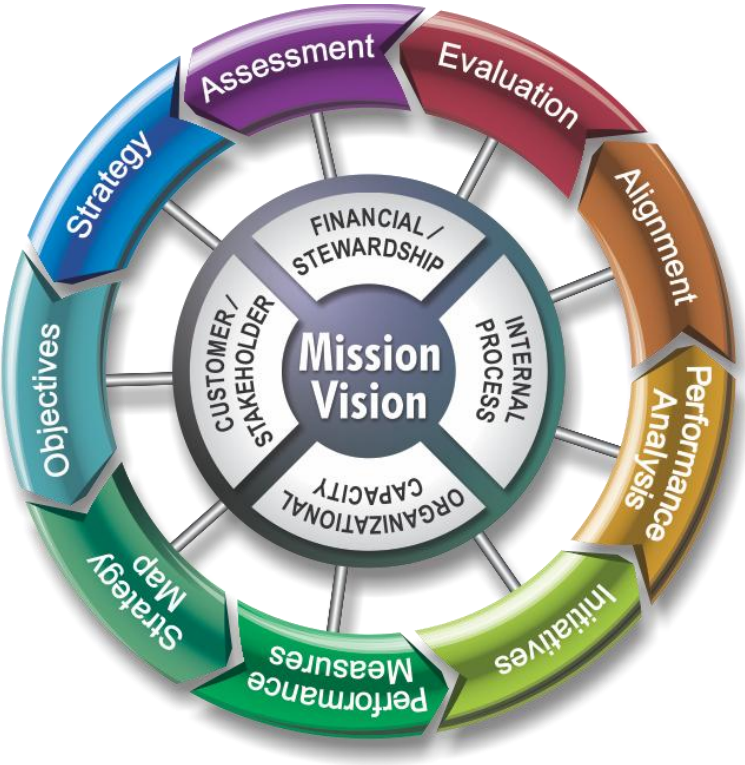

Fig 4: BSC building Steps, Source: Balanced scorecard institute [18]

\subsubsection{Step one: Assessment}

The first step to build a BSC is assessing Mission, Vision, and values of the organization, creating a change management plan, along with conducting a focused communications workshop to identify the required actions. Thus, this step includes the following major elements:

- Prepare the BSC development plan,

- Define the enterprise's current strategic elements,

- Document the procedures followed by the management in the evaluated system

\subsubsection{Step two: Strategy}

The SPM workshop members develop the organization's strategy elements - including Strategic Results, Strategic Themes, and Perspectives - in order to draw attention to the customer needs. The main key elements in this step are:

- The enterprise customer value,

- The enterprise strategic themes,

- The strategic results that should be focused on for the enterprise 


\subsubsection{Step three: Objectives}

After developing the strategic elements to form Strategic Objectives -the basic building blocks of strategy - they are categorized based on the Strategic Theme level by Perspective, then connected in a Strategy Map using causeeffect connections, and finally formed in a consistent output for the whole organization.

\subsubsection{Step four: Strategy Map (Cause \& Effect Connections)}

The Cause \& Effect connections among strategic objectives are created. Strategy Map is important as it defines how an organization creates value for its customers and stakeholders, and the dependencies between achieving objectives targets on other objectives in the map.

\subsubsection{Step five: Performance Measures}

Step five is creating Measures for each Strategic Objective and identifying lead and lag measures, targets and thresholds, and finally, baseline and benchmarking data are developed.

\subsubsection{Step six: Initiatives}

Step Six is to develop Initiatives that support the Strategic Objectives. Forming accountability in the organization is created by assigning ownership of Performance Measures and Strategic Initiatives to the appropriate staff, and documenting this in data definition tables.

\subsubsection{Step seven: Performance Analysis}

\section{(Evaluation Interpretation and Intelligence)}

The implementation process starts by applying performance measurement software in order to get everything in its right place and correct order. Implementing BSC using Automation helps transform corporate data into information and knowledge, and offers instant access to real performance data leading to making better decisions.

\subsubsection{Step eight: Alignment (Cascading)}

The enterprise-level scorecard here is 'cascaded' into smaller levels like business unit, support unit, and it keeps cascading till it reaches team and individual scorecards (which links daily activities to the department goals). Cascading provides alignment within the organization, as it translates high-level strategy into lower-level objectives, measures, and operational details. Once the scorecard is cascaded down through the organization, objectives become more operational, and thus, it is important to specify the accountability for objectives and measures, define Ownership at each level, and communicate results throughout the organization.

\subsubsection{Step nine: Evaluation}

The final step is to evaluate the scorecard, in which the organizations should answer such questions: Does these strategies work?', 'Are the right things being measured?' 'Has the environment changed?' and 'Is the money strategically budgeted?'

Based on these 9 steps, building a BSC system starts with assessment till it reaches the evaluation phase. In this paper, these 9 steps were used as a reference to build the plan for applying the BSC on the target enterprise.

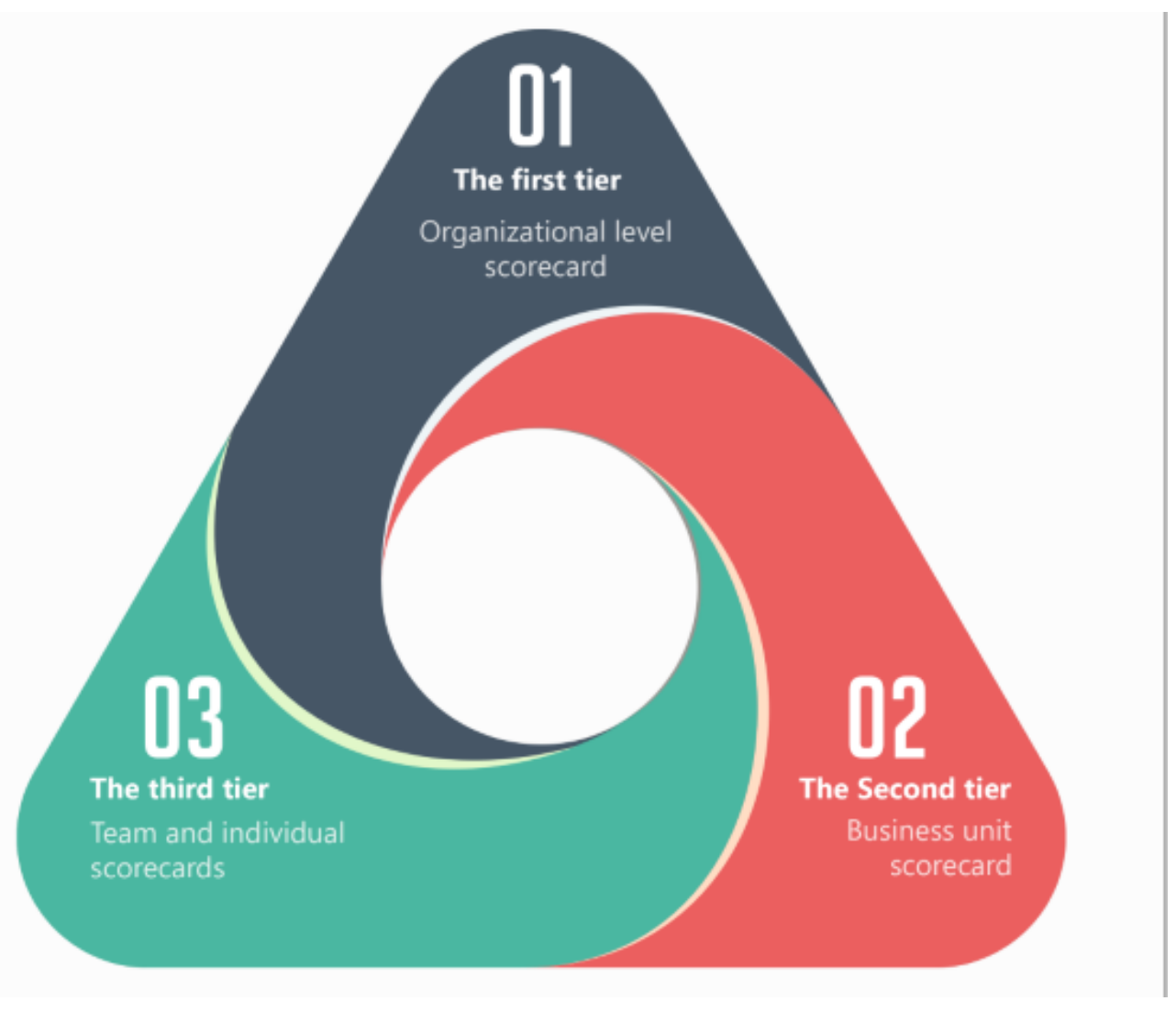

Fig 5: BSC levels 


\section{BSC PLAN PHASES}

After the preliminary discussions with the top management, a full plan for implementing the BS was submitted. The plan included the stages of implementing the civil aviation information and technology enterprise performance measurement system using BSC measurement tool.

The plan lists all the followed phases and activities to achieve actual results that will help in the decision making, bearing in mind the results presentation and the output dashboards that represent the objectives achievements percentages, and thus, allow taking new initiatives by the strategic management after evaluating the current performance for the enterprise. The suggested plan consists of four main stages as illustrated in figure 7.

\subsection{Phase 1: Current system data collection and documentation}

In this phase, a there will be tracking to all the selected departments processes and workflows in order to document what's in hands right now. This includes, but is not limited to:

1. List the vision, mission, goals, values, who we are statements, .etc.

2. Organization structure (departments, and their relations and work flows).

3. List of all inputs, deliverables and needed output for each department.

4. Document success stories, best practices, and most effective corrective actions.

5. Evaluate the current system (to specify the weaknesses and current constraints)

6. Specify the main departments to implement the strategic performance measurement and management system

In order to make the measurement process efficient, there are sets of supporting activities that will take place, for example:

- Distributing a survey among the departments' employees to learn how well do the employees adapt to the strategy and how can they be incorporated into the measurement system.

- Documenting action items for the evaluation measurements on a frequent basis in order to have an effective and accurate BSC measurement system.

- Including the relevant stakeholders in all steps over and over in order to have their hands in while documenting the system.

- Documenting strength and weakness points continuously.

\subsubsection{Phase 1Outputs}

- Understanding and documenting full Processes,

- Defining the Strategic objectives to be measured by the current and the suggested KPIs,

- Collecting all available KPIs,

- Defining the connections among the objectives,

- Aligning the objectives to the perspectives,

- Aligning KPIs to the strategic objectives,

- Preparing survey to measure the strategic alignment and performance results interpretations by top and mid management.

\subsection{Phase 2: BSC Modeling}

After collecting all required data and specifying the main departments, stakeholders, strengths and weaknesses, an interpretation of all the gathered data into the BSC model will be started at this stage.

Here, the exact Objectives under each perspective will be specified, and for each objective all the related key performance indicators will be assigned as well. This phase will include the following in order:

1. Define and list the four Perspectives for AVIT (in order to accurately link the related objectives that serve each perspective).

2. Define the strategic objectives under each perspective.

3. Define the measurement (Key Performance Indicators) for measuring the performance of each Objective.

4. Define the initial management initiatives and actions needed at the current stage.

Key Performance Indicators (KPI), also known Key Success Indicators (KSI), helps organizations define and measure progress and ability to achieve their goals. KPIs are countable measurements that depend on the nature and requirements of the business. [15]

KPIs make the complicated nature of organizational performance easy to understand by using a small number of key indicators, which is basically the same approach people use in their daily lives. KPIs do the same as what a doctor does when a patient goes to him. He measures blood pressure, cholesterol levels, heart rate and your body mass index as health key indicators.

\subsubsection{Phase 2 Outputs}

- Full BSC model with all perspectives, objectives and KPIs aligned and validated,

- Full Strategy map with the cause and effect relations among KPIs.

\subsection{Phase 3: Defining and inserting measurement values}

For each KPI, the following values should be defined:

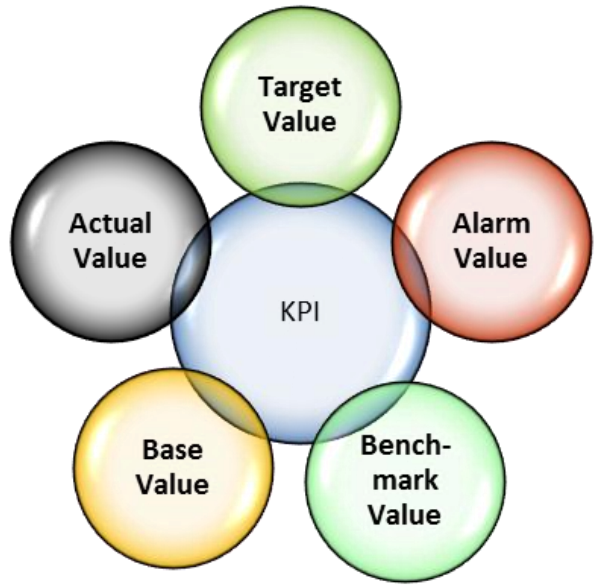

Fig 6: KPI properties / values

- Defining the alarm and target values is crucial to guarantee an accurate and realistic measurement.

- The base value is the initial value or the average value for a specific KPI in the organization.

- The benchmark value is the value that the companies are achieving as a standard value. 
- The actual value is the current value for a KPI (which will be compared to the alarm and the target values) to detect whether the current performance is above or below the target for a specific KPI and for the whole Objective.

\subsubsection{Phase 3 Outputs}

- Very accurate target values have to be assigned to each KPI,

- Defined periods for measuring the values against the targets (monthly, Quarterly, Annually, and Semiannually),

- Continuous management involvement is extremely required at this stage.
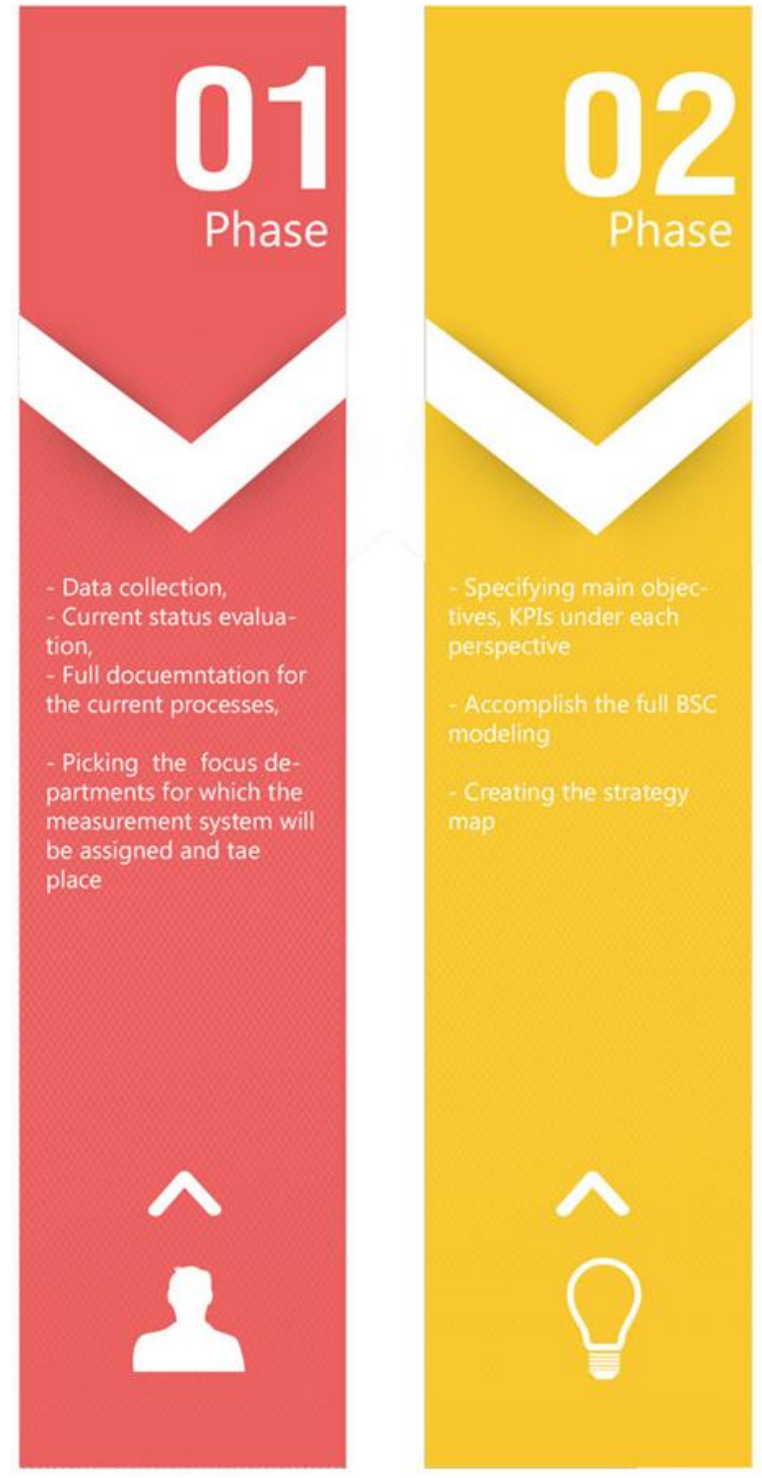

\subsection{Phase 4: Output Dashboards and reports, Management initiatives and actions}

This is the final stage where the performance will be measured, and the final reports will be generated for the management. At this stage, the management is required to make correctives actions, preventive actions, and even reevaluation of how the Objectives are measured, some KPIs may need to be changed, Target Values will be adjusted if necessary. Accordingly, the Initiatives will be turned into action plans with specific deadlines to meet new targets and to prevent bad performance figures.
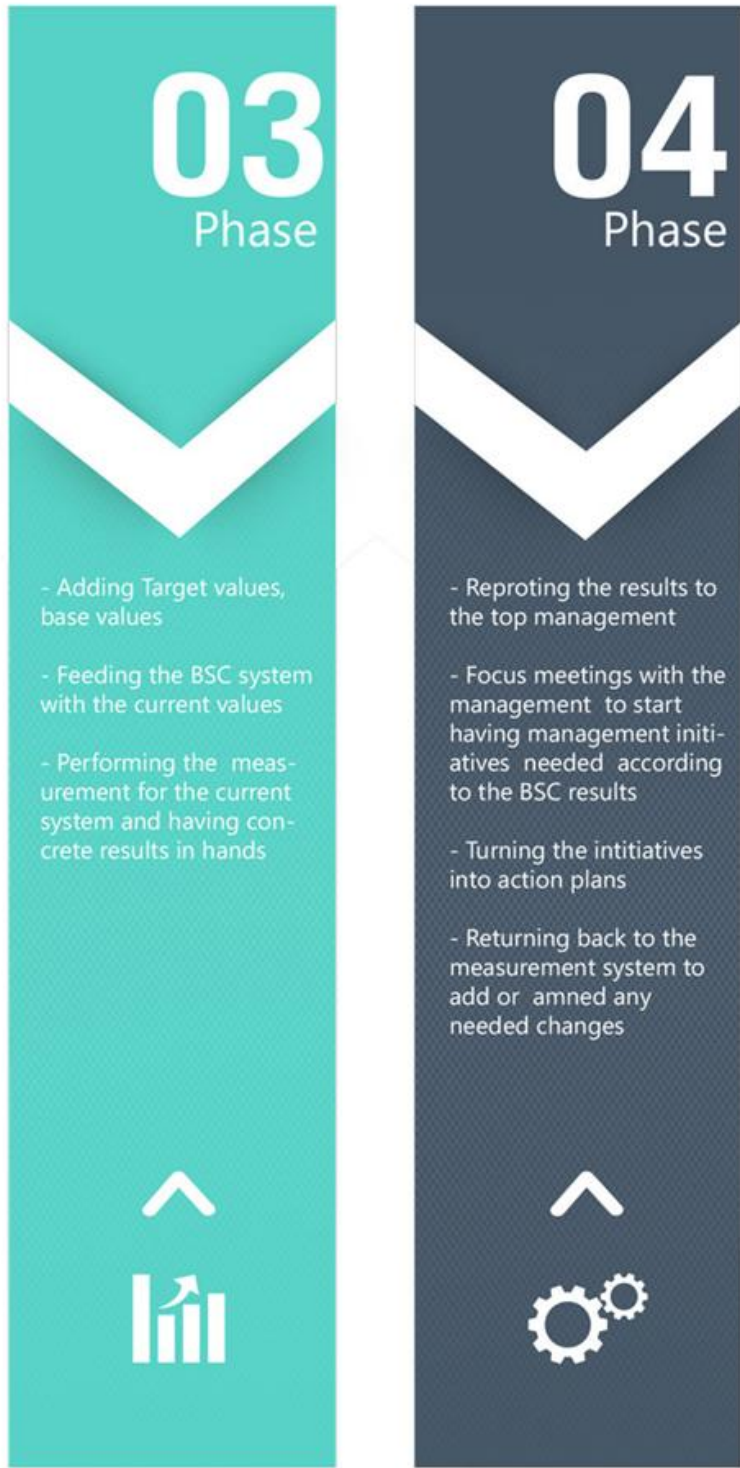

Fig 7: Implementation phases

By implementing the above plan, the following will be achieved:

- Full integration of the performance measurement mode generated by the BSC with the enterprise strategy,

- A consistent strategy map that draws the full relation among the objectives,
- Definition of long term strategic mission (3-5 destination statement) which encompasses the strategic targets towards the stakeholders, cutover relations, process improvements and organization functional development. [24] 


\section{Phase 1: Data collection and evaluation for the current} status

After conducting the meetings with the strategic management in the IT arm in the civil aviation, the first step followed was the full documentation for the current status and its evaluation. The organization had the following mission and vision statements:

\section{MISSION "as stated in the organization profile"}

"Offer our customers the most innovative and competitive ICT products, services, and solutions, especially designed to serve their sophisticated needs and business requirements"

\section{VISION "as stated in the organization profile"}

AVIT (Aviation Information Technology) subsidiary has been established to provide such technological solutions with a broad wide vision to be: A leading IT Company in the aviation field, providing High Quality State-of-the-Art technology to Local, Regional and Global Market.”

\section{The key competencies for the organization:}

- Full Solution Provider: System Integration, and consultation.

- Reliable: having a Solid Financial Foundation.

- Trustable: Being a governmental entity under the supervision of the Ministry of Civil Aviation.

- Profound knowledge in understanding the Aviation Sector's unique requirements.

- A Leading Provider of technical support \& SLAs.

- A Complete Services' portfolio.

The above key competencies will be used in the measurement system to verify if they are really measured or not, and if they are measured what are the measurement KPIs, and if they are best selected and defined to measure the competencies for the company

\section{CASE UNIT STATUS EVALUATION}

The company profile was very specific, short, and doesn't have any clear strategy, strategic objectives, or goals.

After conducting many interviews on the operational and strategic levels, many problems were clear and could be defined, such as:

- The implemented projects have no references for customer satisfactions, process flows for the customers feedbacks handling.
- There are no performance indicators assigned to strategic objectives, thus, no corrective actions are assigned to the performance measurement followed in some departments.

- There is no reporting system for the high level managers, so the performance is not communicated properly to the management, and accordingly no decisions are taken to enhance the performance.

- There is no basis for target settings, the target values are preset and are not changed annually based on the results.

- There is no mapping framework assigned to define the relations among the business processes, performance measurements, and performance results. Hence, no causes and effect relations are specified to identify the root cause for the problems, weakness point in the system, and/or critical success factors.

- Employees are unaware of the organization's visions or strategic direction.

- The project management process is not well defined or communicated with the other processes, such as maintenance, marketing, and customer support.

- There are no preset targets for the individuals performances, in addition, employees are unaware of the followed process to evaluate them, which encompasses the job descriptions definitions, and tasks being assigned to them.

- The KPIs reporters are not fully aware of how to measure the performance, causing incomplete and inaccurate performance reporting.

Since it was difficult to get the history data of the currently defined KPIs as well as the suggested KPIs to be used to enhance the performance in this phase, it was necessary to specify the relations between the internal processes and departments. Figure 8 specifies the connectors among the departments, which leads accordingly to specify the strategy map that displays all strategic objectives and the cause and effect relations among them.

Figure 8 presents a high level perspective for the interaction between the processes and the interaction code for each of the quality models followed in the company. In spite of having such types of interactions and modeling, no further documentation was available for a deeper view of the internal process flow in the organization, and there was a difficulty getting such details due to its confidentiality. 


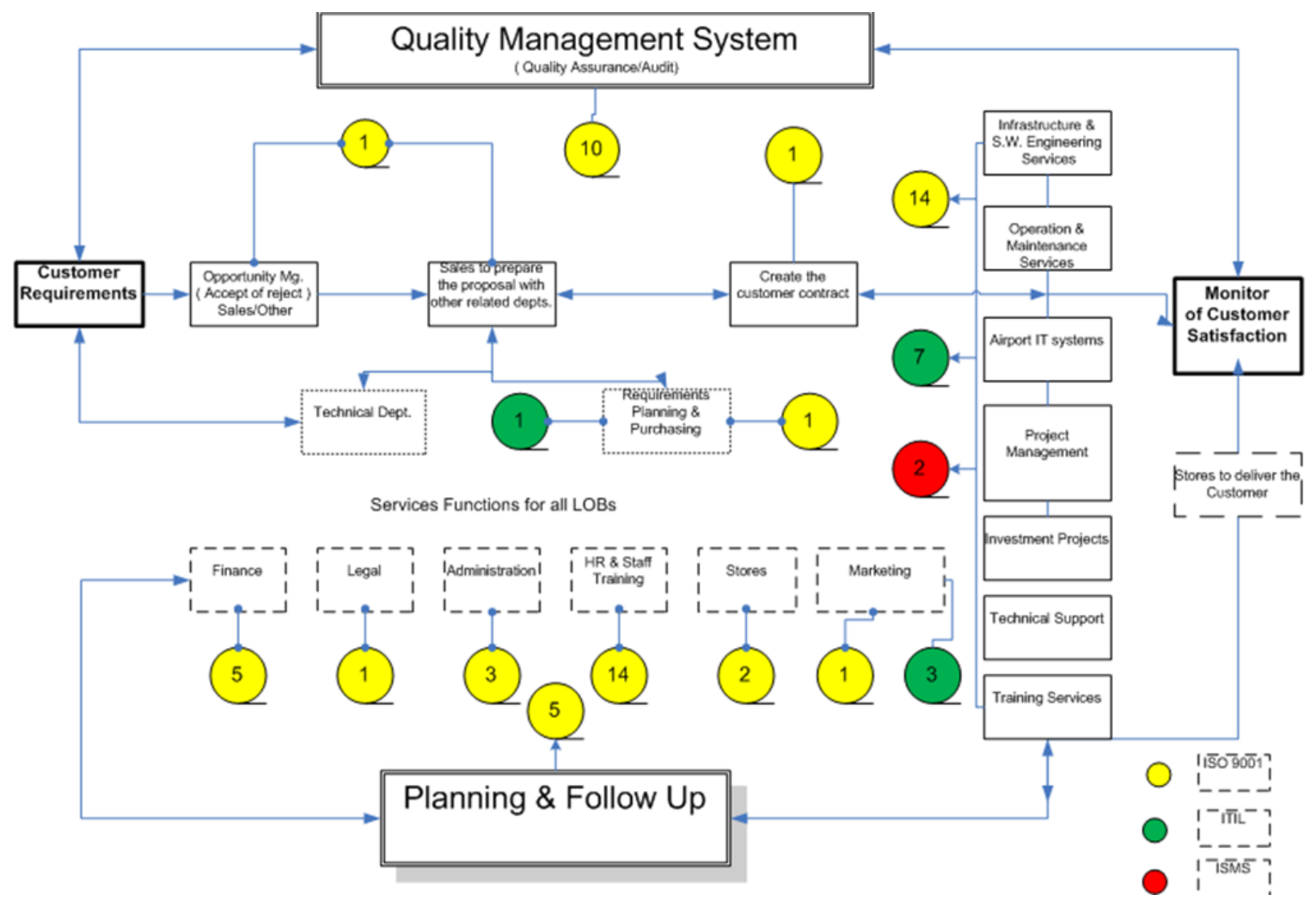

\subsection{Performance Measurement current}

\section{status}

Performance measurement all over the organization depended on some metrics that have the same calculation pattern, without defined relations or weights for each one, and no defined plans if they did not achieve their targets. Measurements were added and calculated in excel sheets, and no output charts to show the measurement status. The table below represents an example of the currently used performance measurement. It was noticed that the KPIs are measured on a monthly basis, yet the performance sheets included the YTD KPIs, which should be the cumulative value or average values from the 4 quarters. Additionally, no sheets were available for the quarterly performance values. It was also observed that some departments have measurement metric defined (without reference or basis of how they were chosen) and some departments did not have any reference measurements metrics or KPIs.

\subsection{Perspectives-Objectives mapping}

As a very important part of phase 1 , it is necessary to define the best fit strategic objective that will be considered the road map for the company's strategy, performance management, and defined relationships between relevant performance drivers.

The following objectives were suggested to the management, after looking at the same ones in the best IT arms companies in the civil aviation sector, the basic strategic objectives could be defined to be used in the BSC development process and in the relevant results reporting using the BI techniques. Below are all objectives assigned to their relevant perspective

Table 2: Defined Objectives for AVIT

\begin{tabular}{|l|l|}
\cline { 2 - 2 } Serial \# & Strategic Objective \\
\hline AV-01 & $\begin{array}{l}\text { Ensuring the existence of appropriate operations and procedures needed to perform quality } \\
\text { projects. }\end{array}$ \\
\hline AV-02 & Improve strategic alignment and awareness and increase accountability. \\
\hline AV-03 & Delivering cost-benefits and revenue based projects. \\
\hline AV-04 & $\begin{array}{l}\text { Accommodate consistent marketing materials and pricing policies (adopting effective } \\
\text { marketing activities). }\end{array}$ \\
\hline AV-05 & Expanding the projects base being developed for the Civil Aviation. \\
\hline AV-06 & Enhancing the quality of the delivered projects. \\
\hline AV-07 & Assessing and identifying recruitment needs for the department and facilitating the required \\
\hline
\end{tabular}




\begin{tabular}{|c|c|}
\hline & training. \\
\hline AV-08 & Obtaining fully fledged training plans. \\
\hline AV-09 & Providing ongoing alternative solutions for achieving the AVIT plans. \\
\hline $\mathrm{AV}-10$ & Providing an effective recruitment process. \\
\hline AV-11 & Developing and applying evaluation systems for all levels in AVIT. \\
\hline AV-12 & Enhancing current procedures that affect the overall targets achievements \\
\hline $\mathrm{AV}-13$ & Providing opportunities to achieve a maximum level of competency in technology \\
\hline AV-14 & Creating a framework to evaluate the services provided by AVIT. \\
\hline $\mathrm{AV}-15$ & $\begin{array}{l}\text { Facilitating and providing a persistent way for communicating information (information } \\
\text { flow) among AVIT departments. }\end{array}$ \\
\hline $\mathrm{AV}-16$ & Providing timely accurate information of products and services for all stakeholders. \\
\hline AV-17 & Expanding sales by getting adequate sales procedures and following innovative techniques. \\
\hline AV-18 & Providing optimum maintenance solutions for the internal and external projects. \\
\hline $\mathrm{AV}-19$ & $\begin{array}{l}\text { Increasing the customer base for AVIT in } 2015 \text { while providing best ways for maintaining the } \\
\text { existent customers. }\end{array}$ \\
\hline $\mathrm{AV}-20$ & Having long term ideas/levels for AVIT to move forward (on timely basis). \\
\hline $\mathrm{AV}-21$ & $\begin{array}{l}\text { Increasing the contribution to and advice on the development, revision and amendments } \\
\text { related to air traffic control and all sister companies' activities in order to ensure adherence to } \\
\text { international standards. }\end{array}$ \\
\hline $\mathrm{AV}-22$ & Increasing Customer engagement and satisfaction. \\
\hline
\end{tabular}

\section{Aligning the defined objectives to the relevant perspectives}

What comes after defining the strategic objectives is aligning each one to its relevant. At this stage, it is necessary that each perspective is well defined and set by its measuring objectives. Then comes another validation dimension, which is finding if the balance is achieved, if any perspective isn't mapped to a set of objectives, then the objectives setting has to be reconsidered to add more relevant -balanced- set of objectives.

Table 3: Objectives-Perspectives Mapping

\begin{tabular}{|l|ll|}
\hline Perspective & Related Objectives \\
\hline Financial & - & Providing opportunities to achieve a maximum level of competency in technology \\
& - & Delivering cost-benefits and revenue based projects \\
\hline Customer & - & Enhancing the quality of the delivered projects. \\
& - & Providing timely accurate information of products and services for all stakeholders. \\
& - & Providing optimum maintenance solutions for the internal and external projects. \\
& - & Developing new business channels with internal and external customers. \\
& - & Increasing Customer engagement and satisfaction. \\
\hline Internal & - & Ongoing enhancements for the procedures that affect the overall targets achievements. \\
Processes & - & Providing an effective recruitment process. \\
& - & Developing and applying evaluation systems for all levels. \\
& - & Ensuring the existence of appropriate operations and procedures needed to perform \\
& & quality projects. \\
\hline
\end{tabular}




\begin{tabular}{|c|c|c|}
\hline $\begin{array}{l}\text { Learning and } \\
\text { Growth } \\
\text { (Innovation) }\end{array}$ & - & $\begin{array}{l}\text { Improve strategic alignment and awareness and increase accountability. } \\
\text { Assessing and identifying recruitment needs for the department and facilitating the } \\
\text { required training. } \\
\text { Obtaining fully fledged training plans. } \\
\text { Increasing the contribution to and advice on the development, revision and amendments } \\
\text { related to air traffic control and all sister companies' activities in order to ensure } \\
\text { adherence to international standards. } \\
\text { Assessing and identifying the department recruitment needs, and facilitating the required } \\
\text { training. } \\
\text { Having long term ideas for AVIT to move forward. }\end{array}$ \\
\hline
\end{tabular}

\subsection{KPIs Mapping}

At this stage, KPIs used all over the organization were gathered, translated into measurement formulas, and mapped to the related objectives. For example, the objective "Delivering cost-benefits and revenue based projects" was assigned to the following KPIs:

- $\%$ Department's Manpower Utilization

- $\%$ Exceeding set durations (Actual versus Planned) (Implementation Phase)
- $\%$ of executed preventive maintenance

- $\%$ Developed Software Engineering Revenue / Costs

For each objective, all related KPIs are assigned, and each KPI formula is then developed to later calculate the performance (which will be mainly a ration of two values P1/P2). The below table represents a snapshot of the data representation for the KPIs and their relevancy to the corresponding objectives.

Table 4: Examples of current KPIs

\begin{tabular}{|c|c|c|c|c|}
\hline KPI & $\begin{array}{l}\text { KPI Owning } \\
\text { Department }\end{array}$ & Measured Objective & $\begin{array}{l}\text { Actual } \\
\text { P1 }\end{array}$ & $\begin{array}{l}\text { Actual } \\
\text { P2 }\end{array}$ \\
\hline $\begin{array}{l}\text { \% signed } \\
\text { Contracts, } \\
\text { Letters of } \\
\text { Award, } \\
\text { Purchase Orders } \\
\text { compared to } \\
\text { Offered }\end{array}$ & $\begin{array}{l}\text { Business } \\
\text { Development - } \\
\text { Sales }\end{array}$ & $\begin{array}{l}\text { Expanding the projects base } \\
\text { being developed for the Civil } \\
\text { Aviation }\end{array}$ & $\begin{array}{l}\text { Number of Signed } \\
\text { Contracts, Letters of } \\
\text { Award, Purchase Orders }\end{array}$ & $\begin{array}{l}\text { Number of Offered } \\
\text { Proposals }\end{array}$ \\
\hline $\begin{array}{l}\% \text { Number of } \\
\text { New Contracts } \\
(\mathrm{Y} / \mathrm{Y}-1)\end{array}$ & AVIT General & $\begin{array}{l}\text { Expanding the projects base } \\
\text { being developed for the Civil } \\
\text { Aviation }\end{array}$ & $\begin{array}{l}\text { Number of New Contracts } \\
\text { (Y) }\end{array}$ & $\begin{array}{l}\text { Number of Contracts (Y- } \\
\text { 1) }\end{array}$ \\
\hline $\begin{array}{l}\% \text { of } \\
\text { Employees } \\
\text { receiving } \\
\text { training (Actual } \\
\text { / Planned) YTD }\end{array}$ & Staff Training & $\begin{array}{l}\text { Assessing and identifying } \\
\text { recruitment needs for the } \\
\text { department, and facilitating the } \\
\text { required training }\end{array}$ & $\begin{array}{l}\text { Number of Employees } \\
\text { trained YTD }\end{array}$ & $\begin{array}{l}\text { Planned Number of } \\
\text { Employees for training } \\
\text { YTD }\end{array}$ \\
\hline$\%$ Absenteeism & AVIT General & $\begin{array}{l}\text { Assessing and identifying } \\
\text { recruitment needs for the } \\
\text { department, and facilitating the } \\
\text { required training }\end{array}$ & $\begin{array}{l}\text { Total Absence Days } \\
\text { (Excluding Vacations) }\end{array}$ & $\begin{array}{l}\text { Head Count Working } \\
\text { Days }\end{array}$ \\
\hline $\begin{array}{l}\text { \% of Customer } \\
\text { letters closed > } \\
\text { Target (by } \\
\text { Department / } \\
\text { Person) }\end{array}$ & $\begin{array}{l}\text { Planning \& } \\
\text { Follow Up }\end{array}$ & $\begin{array}{l}\text { Providing optimum maintenance } \\
\text { solutions for the internal and } \\
\text { external projects }\end{array}$ & $\begin{array}{l}\text { Number of Letters closed } \\
\text { late exceeding Target }\end{array}$ & $\begin{array}{l}\text { Total No of Customers } \\
\text { Letters received during } \\
\text { the period }\end{array}$ \\
\hline $\begin{array}{l}\text { \% of Customer } \\
\text { letters closed > } \\
\text { Target (by } \\
\text { Department / } \\
\text { Person) }\end{array}$ & Procurements & $\begin{array}{l}\text { Providing optimum maintenance } \\
\text { solutions for the internal and } \\
\text { external projects }\end{array}$ & $\begin{array}{l}\text { Number of Letters closed } \\
\text { late exceeding Target }\end{array}$ & $\begin{array}{l}\text { Total No of Customers } \\
\text { Letters received during } \\
\text { the period }\end{array}$ \\
\hline
\end{tabular}




\begin{tabular}{|l|l|l|l|l|}
\hline $\begin{array}{l}\text { Revenue / } \\
\text { Employee } \\
\text { Actual / } \\
\text { Planned) }\end{array}$ & AVIT General & $\begin{array}{l}\text { Providing an effective } \\
\text { recruitment process }\end{array}$ & $\begin{array}{l}\text { Revenue / Employee } \\
\text { (Actual) }\end{array}$ & $\begin{array}{l}\text { Revenue / Employee } \\
\text { (Planned) }\end{array}$ \\
\hline $\begin{array}{l}\text { \% Attrition } \\
\text { Rate } \\
\text { "voluntary" }\end{array}$ & $\begin{array}{l}\text { Human } \\
\text { Resources }\end{array}$ & $\begin{array}{l}\text { Providing an effective } \\
\text { recruitment process }\end{array}$ & $\begin{array}{l}\text { Number of Voluntary Head } \\
\text { Count Separated }\end{array}$ & Total Head Count \\
\hline $\begin{array}{l}\text { Control } \\
\text { violations }\end{array}$ & AVIT General & $\begin{array}{l}\text { Providing an effective } \\
\text { recruitment process }\end{array}$ & $\begin{array}{l}\text { Numbers of discipline } \\
\text { violations }\end{array}$ & Headcount \\
\hline $\begin{array}{l}\text { \% Customer } \\
\text { Reaining Plan }\end{array}$ & Training Center & $\begin{array}{l}\text { Providing timely accurate } \\
\text { information for products and } \\
\text { services for all stakeholders }\end{array}$ & $\begin{array}{l}\text { Number of realized } \\
\text { Training Courses }\end{array}$ & $\begin{array}{l}\text { Total Planned Training } \\
\text { Courses during the } \\
\text { period }\end{array}$ \\
\hline
\end{tabular}

\section{CASE STUDY RESULTS \& DISCUSSION}

After discussing the case study setup, case unit, and gathering the necessary data form all stakeholders to build a performance BI measurement system, this chapter discusses the processing for this data. The goals of this study are to build a balanced performance measurement system with BI techniques to find out the performance gaps, and to detect the improvements possibilities. Moreover, the researcher will be monitoring and analyzing the historical values, and comparing the performance values and predicting the performance trends. The major focus is to link BSC to BI to maximize the performance output and data presentations in order to build a coherent roadmap and achieve more success in the future. The main output from this study is to have an innovative performance measurement system which is value based, focusing on the future by considering improvement opportunities, and its scope is not only evaluating but also motivating all organizational levels to be aligned to the strategic goals and enhance the productivity on all levels. Thus, the output PMS will encompass and refer to the entire system of performance indicators, starting with elementary indicators which are then summarized into intelligent dashboards. [24]

\subsection{General description and analysis}

The main goal of this study is to build a BI based performance measurement framework with a target of not only to increase the organization's overall performance, but also to predict what are the coming opportunities and threats, and to take corrective actions and actual effective management initiatives. After having the data organized in the BSC context, high profile analysis for this data should be created in order to get the proper KPIs values, and additionally to present the performance status in the most proper way. Accordingly, the researched evaluated the current KPIs and assessed their historical values to conclude the results, then a re-evaluation and validation for the results had to be done.

As figure 9 illustrates, the performance measurement cycle started with defining the objectives, aligning them to the current KPIs, then the real measurement takes place. Results are then represented in the dashboards, and are investigated using charts in order to understand the performance patterns and know where does the company stand at the moment of applying the measurement system. The BI approach here is to use dashboards, charts along with the BSC context to analyze and learn the performance results, and then initiate potential improvements and define new management initiatives and action plans.

\section{Performance measurement lifecycle}

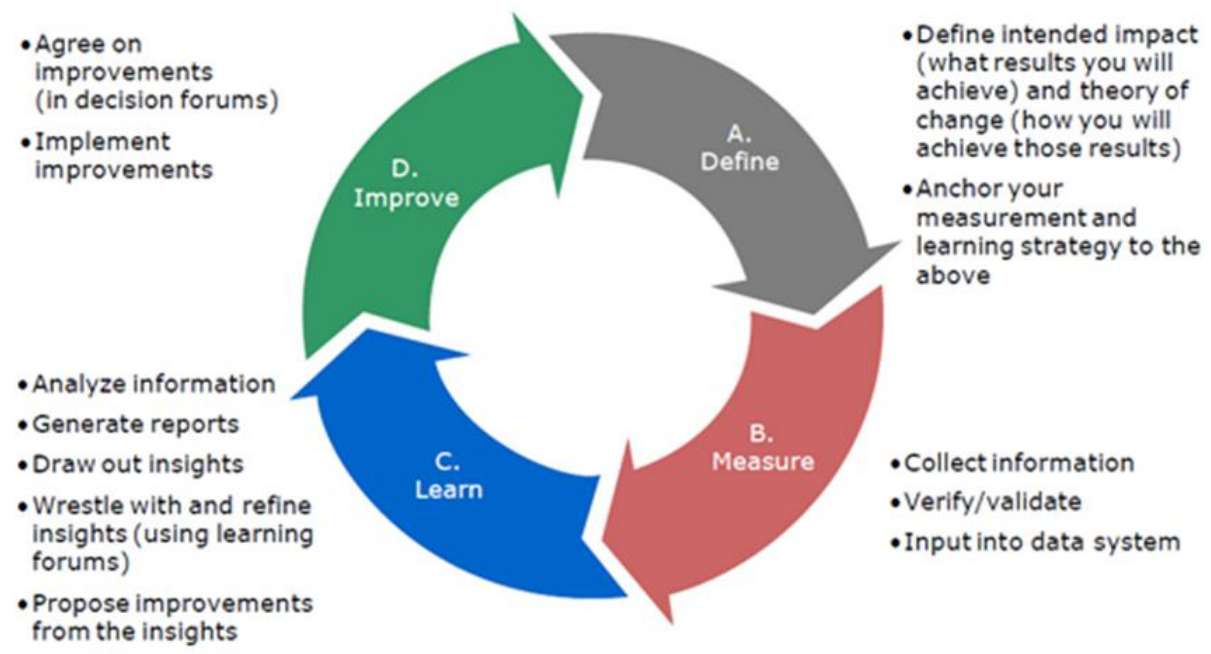

Fig 9: Performance measurement life cycle [19] 


\subsection{Building Strategy Maps}

"Strategy Maps Capture your Strategy and Set the Agenda". [22]

Strategy map is designed mainly to portray the management's thoughts, choices and goals. In only a single page, a welldesigned strategy map can demonstrate these thoughts and choices, and how will the strategy make the changes to reach these goals. Strategy maps focuses on the little things that will create the bigger change in an organization.

For the case unit, a key goal of the BSC is to have a supported measurement framework for the next five years. Thus, a good implemented BSC would be cascaded to all other units, which will affect the overall civil aviation performance. To have a long term built BSC, the organization must define its vision, strategy map, its "tangible future" with all its strategy, risks, and decisions to change in the same timeframe. It must describe through strategy map how to achieve this change.
Consequently, the strategy map frames its BSC to support the strategy.

Strategy maps describe how organizations create value by building on strategic themes such as "growth" or "productivity". Such themes define what strategies the organizations will implement at the levels of process, customer, and learning and growth. A well-built map defines how an organization plans to reach the goals set for its customers, using a mixture of connections between the strategic objectives.

Strategy map-based BSC focuses on how the strategy will improve and change the organization's performance. It not only captures the operational detail as part of the approach, but also it draws the organization's attention to the management and implementation of the strategy. [22]

The below figure illustrates the steps to create a Strategy mapbased BSC, and how does that affect the flow of the processes validation, strategy validation and targets specifications.

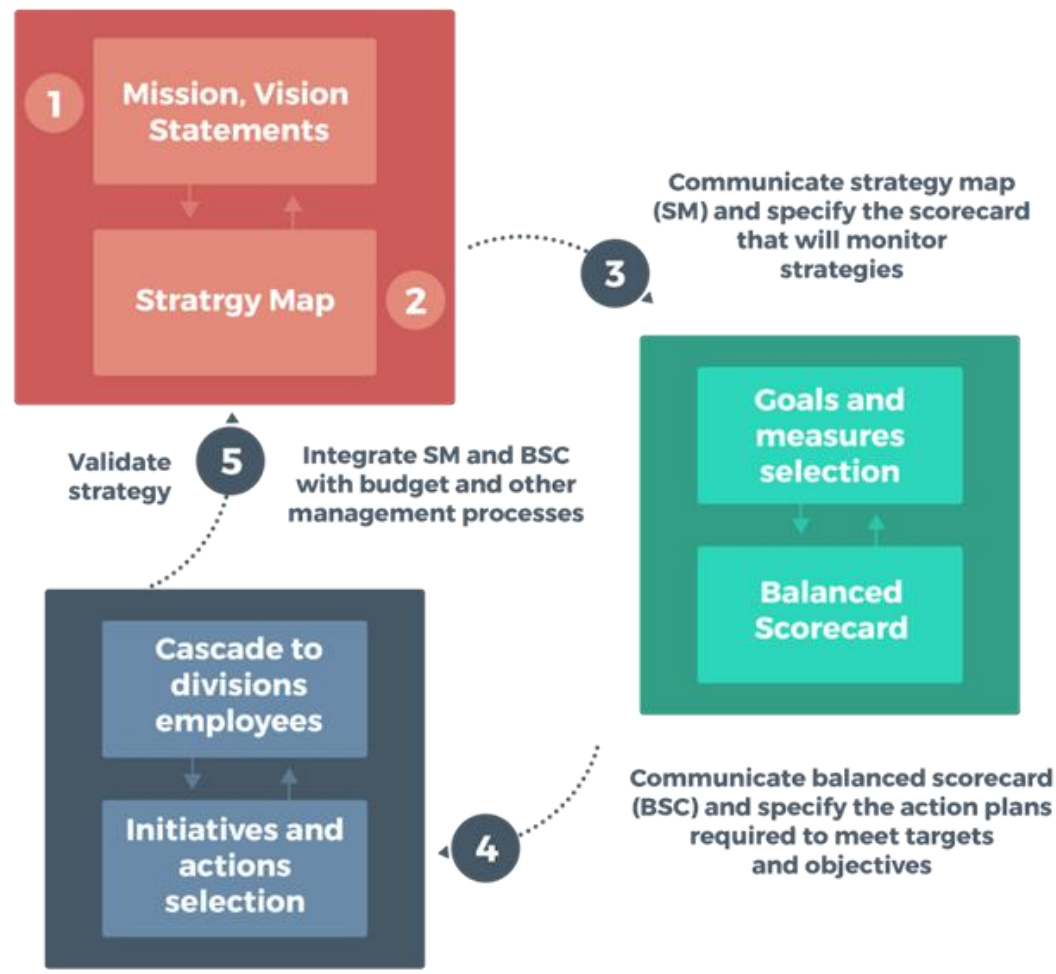

Fig 10: Using strategy maps to drive performance [12]

Figure 11 presents the built strategy map for the civil aviation IT arm, where the relations between the objectives are identified as cause and effects relations. The causes reflect on the performance of the effects objectives, accordingly, this enables identifying what objectives affect the performance of others. This strategy map describes how change will happen, what are the changes sources, and what are the starting change points as strategy is about change. The strategy of case unit (IT services company in the civil aviation) needs to describe what will bring about that change. 


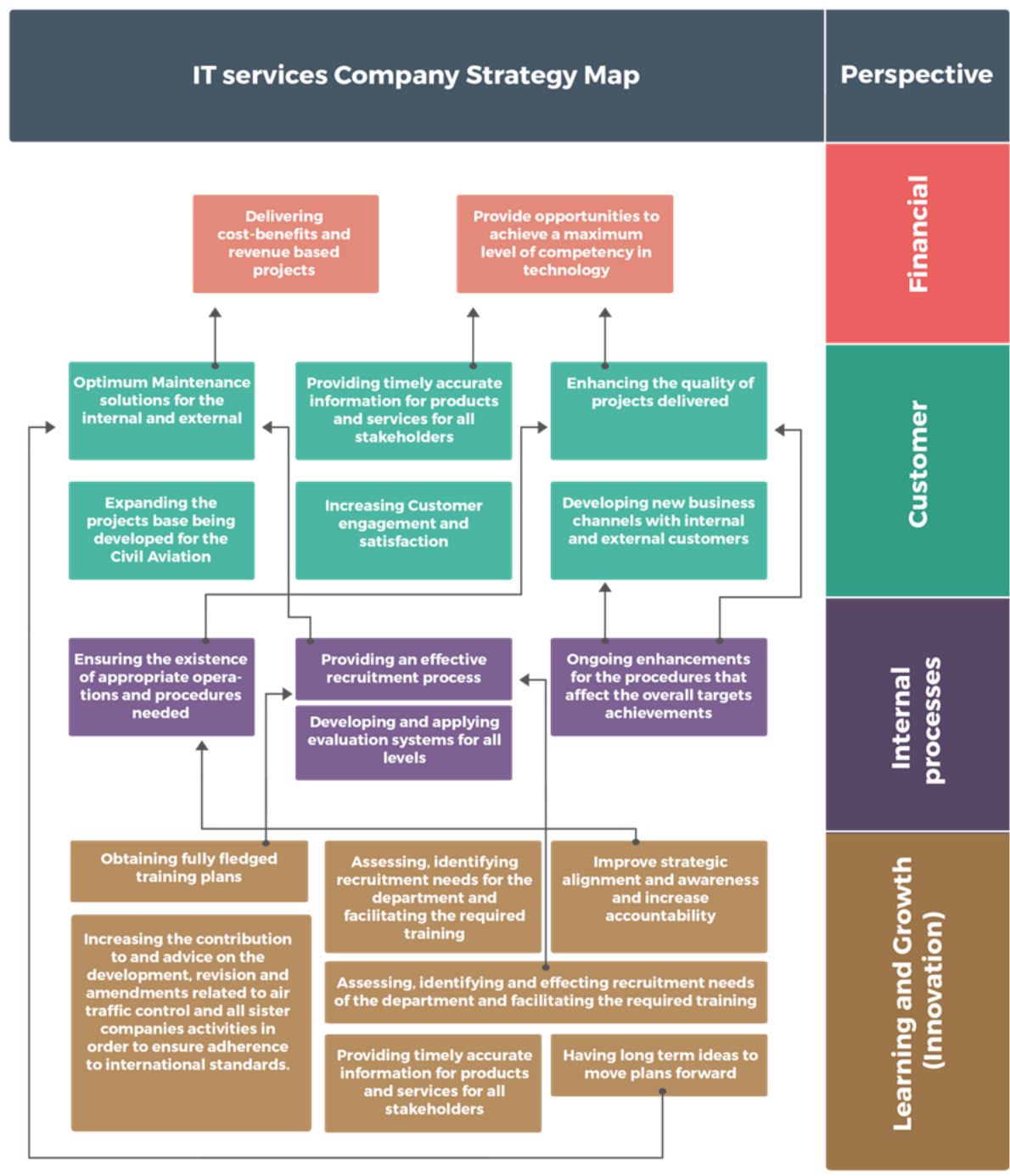

\subsection{KPIs Evaluation}

Spreadsheet is one of the basic BI tools used to study the behavior of the KPIs defined in the case unit. The main objective of the KPI evaluation is to:

- Ensure that the KPIs are eligible for the specified objectives,

- Study the behavior of the KPIs values, and draw their trends for at least one year to have a clear indicative view for the targets achievements or status,

- Have an outlined status for the objectives achievements,
Fig 11: IT services company Strategy Map

- Find and replace the non-fitting KPIs in the performance framework with new more efficiently defined KPIs,

- Define new management initiatives and action plans according to the KPIs evaluated performance.

After having all KPIs data gathered, the target values were plotted after calculating each KPI's performance according to a preset formula for the target calculation in each department. For each KPI, a set of values were gathered from each department and the properties that were aligned for each KPI as presented in table 5 .

Table 5: Case unit adopted KPI Properties

\begin{tabular}{|l|l|}
\hline \multicolumn{1}{|c|}{ KPI Data Field } & \multicolumn{1}{c|}{ Description } \\
\hline $\begin{array}{l}\text { Source } \\
\text { Department/Function/ line } \\
\text { of business }\end{array}$ & The department or business line for which the KPI will be assigned and calculated. \\
\hline Department Code & $\begin{array}{l}\text { A unique code by which the department's data and performance results will be } \\
\text { queried. }\end{array}$ \\
\hline
\end{tabular}




\begin{tabular}{|l|l|}
\hline 'KPI Owning Department & The department responsible for achieving the KPIs targets \\
\hline Actual P1 & $\begin{array}{l}\text { The number for the left hand number value for the KPI (knowing that the final } \\
\text { performance is calculated as P1/ P2) }\end{array}$ \\
\hline Actual P2 & $\begin{array}{l}\text { The number for the right hand number for the evaluation formula (knowing that the } \\
\text { final performance is calculated as P1/ P2) }\end{array}$ \\
\hline KPI Type & $\begin{array}{l}\text { The frequency period where the KPI actual data is gathered and calculated, then } \\
\text { referenced to the target (it is either Monthly, Quarterly, semi Annually or Annually). }\end{array}$ \\
\hline KPI Target $=\mathrm{T}$ & The current needed achieved value, the target value for each KPI. \\
\hline Actual P1 value & The actual collected P1 value for each KPI. \\
\hline Actual P2 value & The actual collected P2 value for each KPI. \\
\hline Actual Result R= P1/P2 & The actual resulted ratio for each KPI. \\
\hline $\begin{array}{l}\text { Achieved Ratio }=\mathrm{R} / \mathrm{T} \\
\text { Ratio (if Type }=-\mathrm{ve}=1-\end{array}$ & $\begin{array}{l}\text { The Actual achieved ratio (the Actual result / Target) } \\
\text { value gets low, the more it gets closer to the target for example the \% }\end{array}$ \\
\hline $\begin{array}{l}\text { Achieved Normalized } \\
\text { The ratio if the KPI's polarity is negative, which means that the more the actual }\end{array}$ \\
\hline
\end{tabular}

Each KPI has four values that were collected in the period of full year, which is 2013. Therefore, the evaluation would take a full year, which is the least time period that can be taken as an evaluation period.

\subsubsection{KPI evaluation patterns}

For all departments, there were around 150 KPIs. Although this was a large number of KPIs, but many of them were following the same trend, for the evaluation to be accurate and to the point a set of patterns were assigned to each KPI group.
6.3.1.1 Large gaps between Targets and Actuals In figure 12, the target is too far from the actual results, which means that the target setting was not efficiently specified or was not realistic or the performance was very bad. Another observation is that the value for the complaints is almost constant, and the same is for the value of the service calls, which is an indicator that the collected values are not realistic, thus, corrective actions are correspondingly suggested.

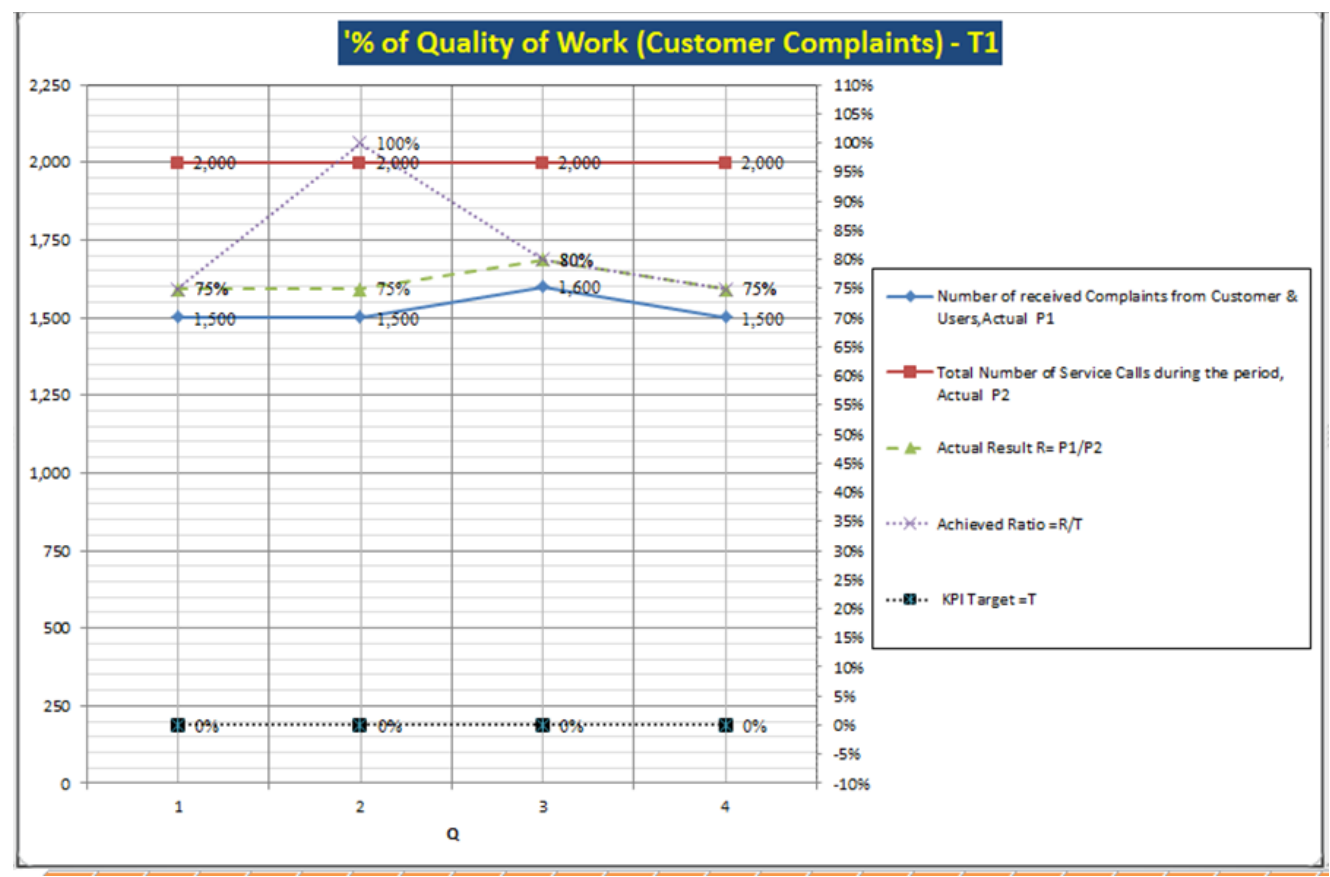

Fig 12: Gaps between Target values and actual values 


\section{Suggested corrective actions:}

- All calls must be tracked and recorded to reach the actual numbers.

- A new target must be specified, and a new complaints criterion must be added (new numbers must be defined for the actual number of complaints per project).

\subsubsection{Actual $=$ Target}

For many KPIs, the actual value is the same as the target value in quarters. It is not logical to have the target value equal to the actual all the time although the overall performance is not really good (according to the management feedback). In figures 13,14 and 15 indicate that the actual values for the four quarters are always equal to the target value - the line of the actual result is placed over the target line. This is not always an indicator that the organization is achieving the targets. Therefore, such KPIs performance value should be checked and reviewed, since this performance behavior may be an indicator for an under estimation of the target values, and a more difficult target value should be set, or this might indicate that this type of KPIs is not important in the context of the performance system, and more convenient KPIs must be defined to achieve a better performance level.

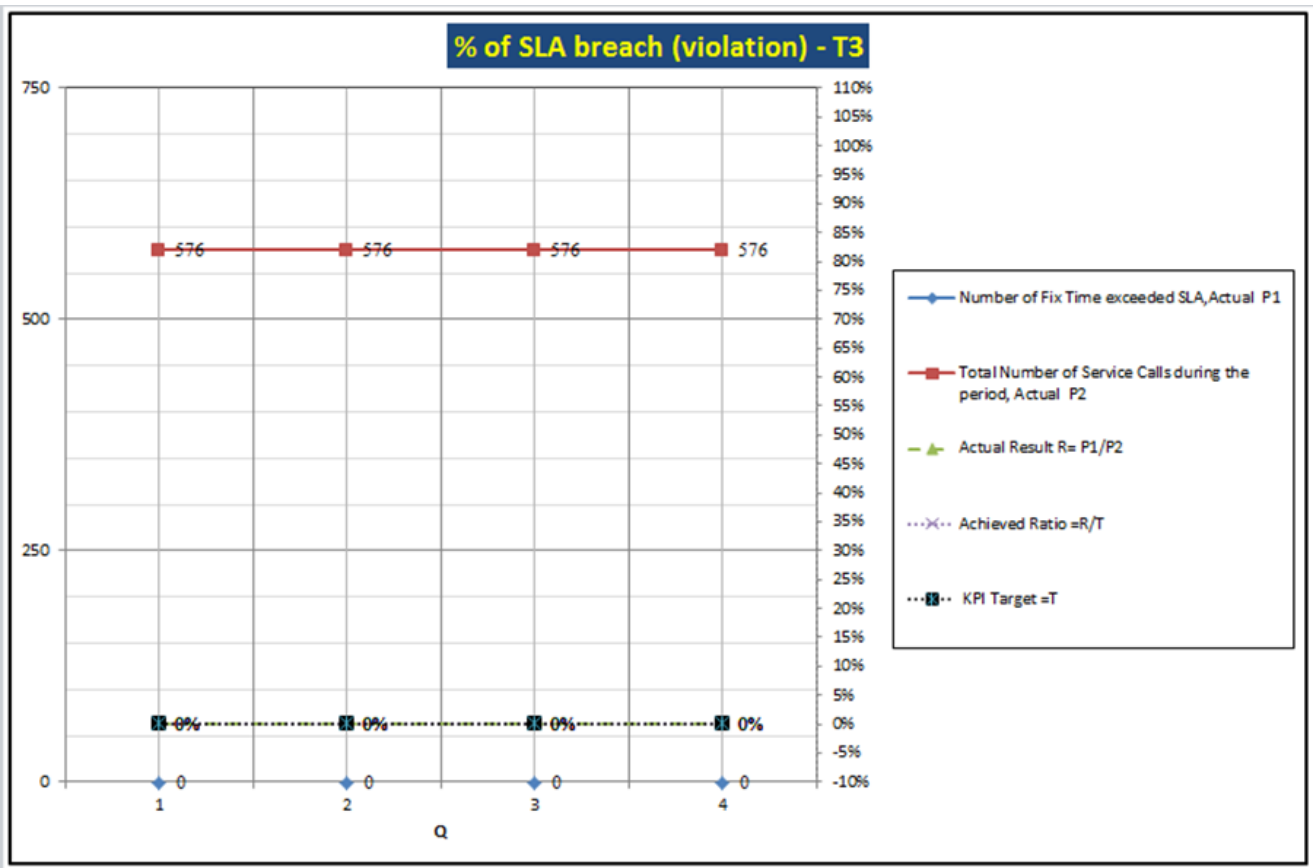

Fig 13: Actual values are the same as target values

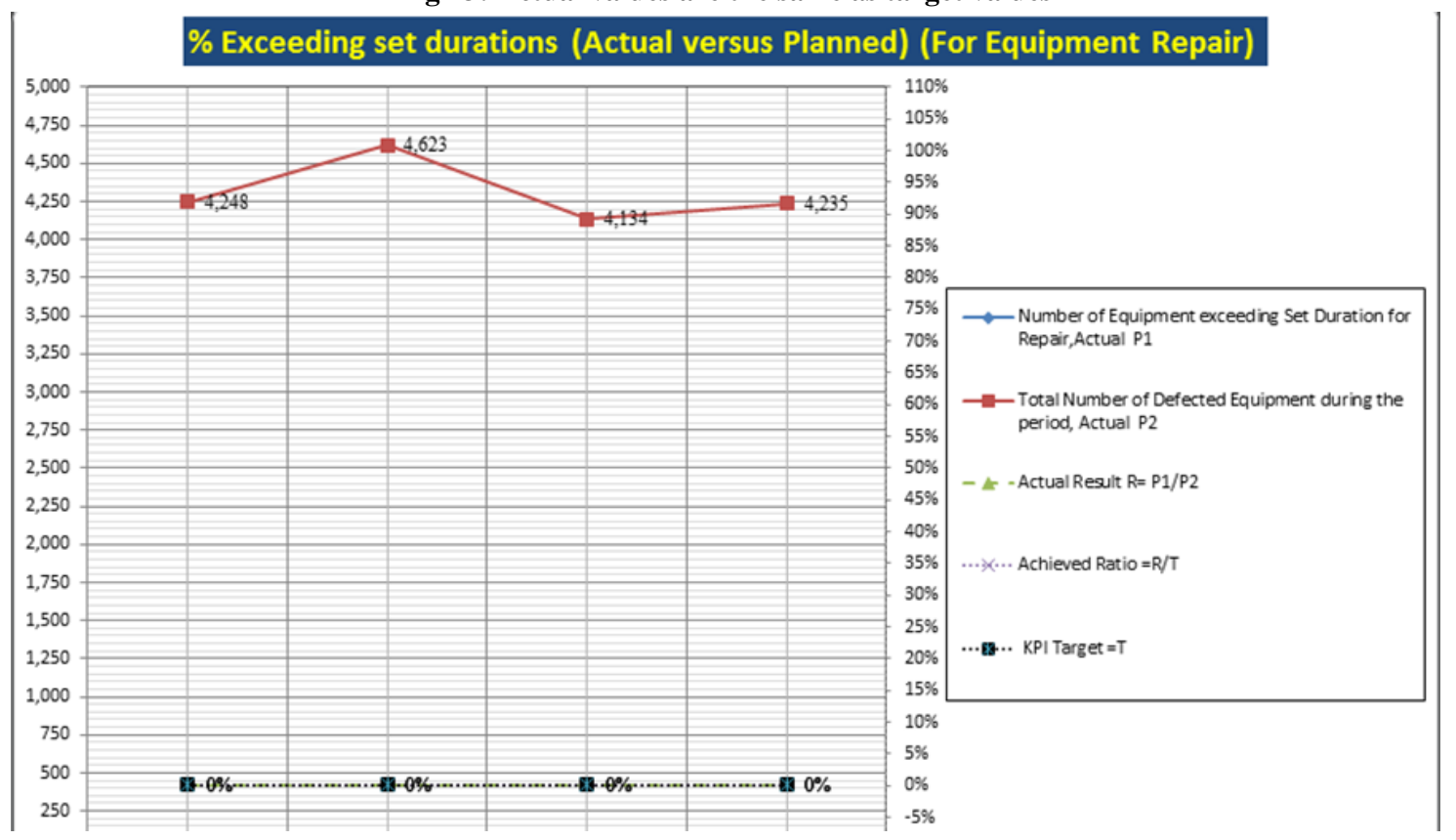

Fig 14: Actual values $=$ target values-continued 


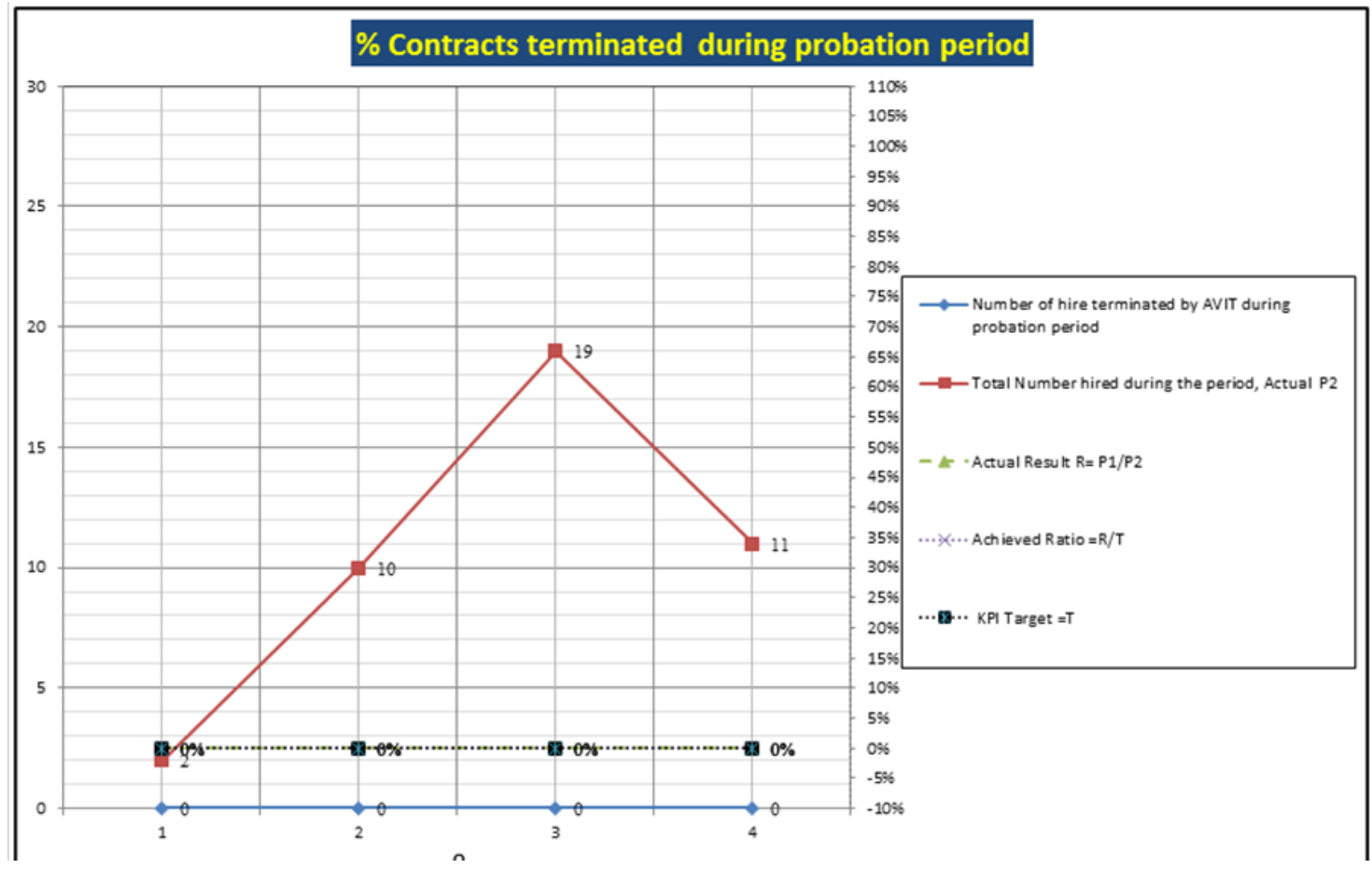

Fig 15: Actual values $=$ target values-continued

\subsubsection{Illogical achievement ratios}

Moreover, some KPIs had illogical achievement ratios. When all values for the targets, actuals and achievement ratio were plotted, the chart line representing the achievement ratios over four quarters was too far from the target and actual values.
This indicates that something is wrong in the target setting. A very good achievement doesn't always mean that the organization is on the right track, hence, some additional values must be tracked, or the formula for calculating the KPI must be re-considered, or the KPI itself can be reformulated.

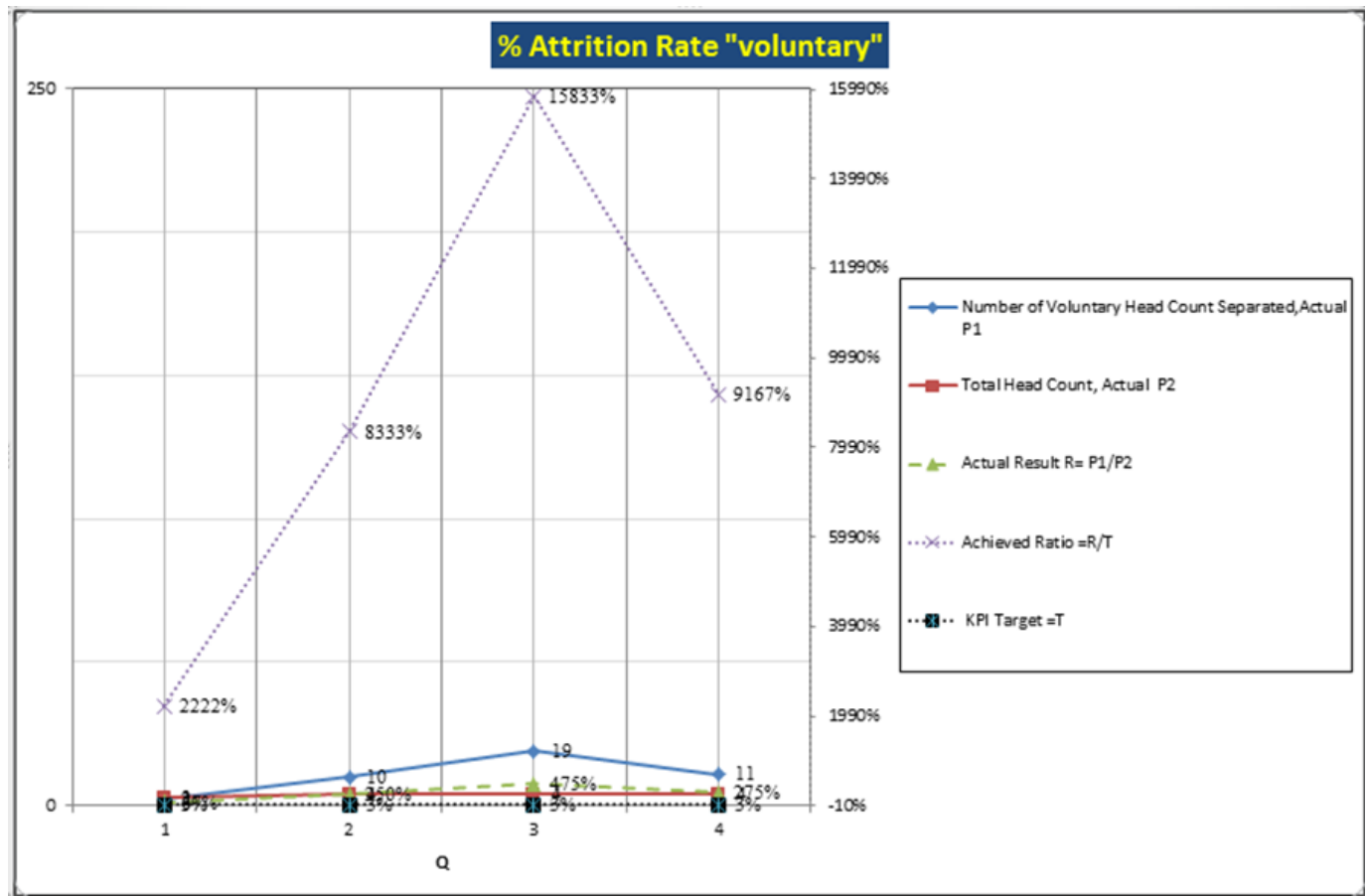

\subsubsection{Inconsistent performance}

Performance trends should have consistent behavior in order to be tracked correctly. For example, for a KPI that measures the staff training plan realization, it is important that the actual results almost have a consistent trend. When this KPI's values were plotted, the actual values were inconsistent as in figure 17. The values are either too low or beyond the targets. So, the needed management initiatives need to evaluate the training department performance and give ad-hoc advices and corrective actions. 


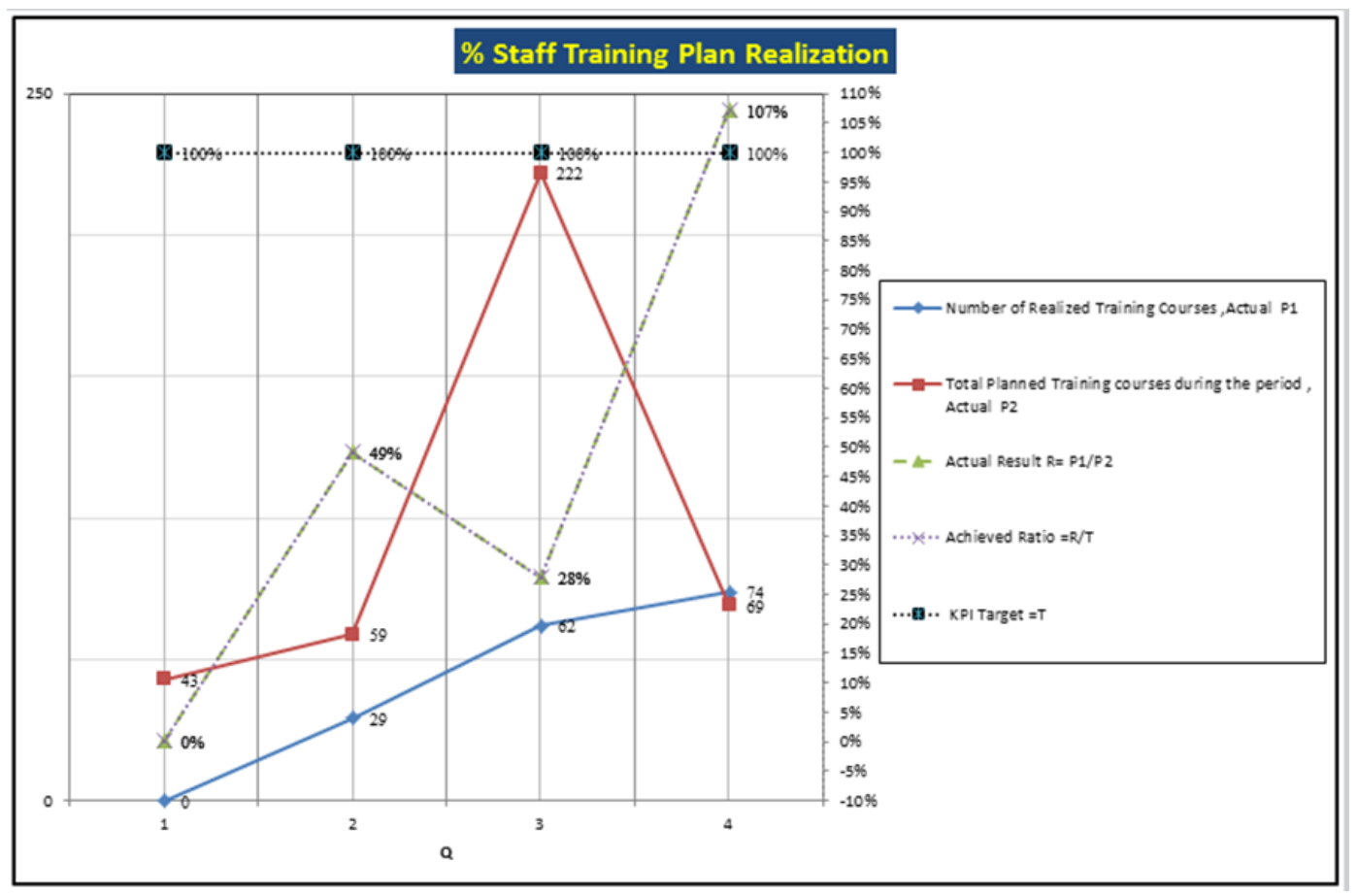

Fig 17: Inconsistent performance

\section{COMPLETING THE FINAL FRAMEWORK ${ }^{1}$}

The final framework with the BSC interpretation is presented along with the output dashboards resulted from the calculation of the objectives' KPIs. BSC Dashboards can be designed to filter out unwanted information to ensure appropriate KPIs are front of mind and relevant to their intended audience. The outcome of a Dashboard application is compelling and can be used to connect to multiple data sources and present the information in a format that is timely, meaningful and actionable. Dashboards also allow users to search, drill down and even update the presented information, as they save time, help reconstruct workflows, maintain the records accuracy, and let users focus their actions on the positive outcome of key metrics. [19]

The goal of this study is to present the performance measurement using the dashboards in the BI context. In this section, the main result is presented. In section 4.3 the spreadsheets chart were used as a BI tool to help study the KPIs performance behavior and to plot the main values for each KPI's main descriptive property. The full BI-BSC output is presented here using the dashboards and KPIs, objective, perspectives performance generators. The full BSC framework is implemented as indicated in figure 18 where the perspectives are aligned to the related objectives, and then aligned to the related KPIs as well, and the KPIs performance was generated. Each one of the generated dashboards for each KPI, objective and perspective was given the performance colors, minimum and maximum values, and the actual results were plotted, the weights for each KPI were assigned equally, and the same goes for both objectives and perspectives.

\footnotetext{
${ }^{1}$ Final Dashboards for the overall performance measurement are presented in this section
}

For each perspective, all objectives are measured. The following snapshots show generated results for each perspective at different dates including 4 historical values, applying BI techniques, and reporting results comes at this stage. In the previous section, the excel charts were generated to manipulate and study the performance trends. The resulted dashboards that were generated from the used software, data for 4 quarters along with the last quarter in 2014 "for the financial perspective" were added to the system. The data representation was in dashboards with tabular formats, and the results were meaningful diagrams that enabled the decision makers to have full vision of the business. Figure 19 presents the final results for the financial perspective that indicated that performance is in the alarm zone, and corrective actions need to be taken to open new business channels. As indicated in figure 20 , this perspective data was periodically reported and evaluated, and in December 2014, the performance was tracked and enhanced to reach the pre-green zone as a direct impact of the periodical performance measurement. 


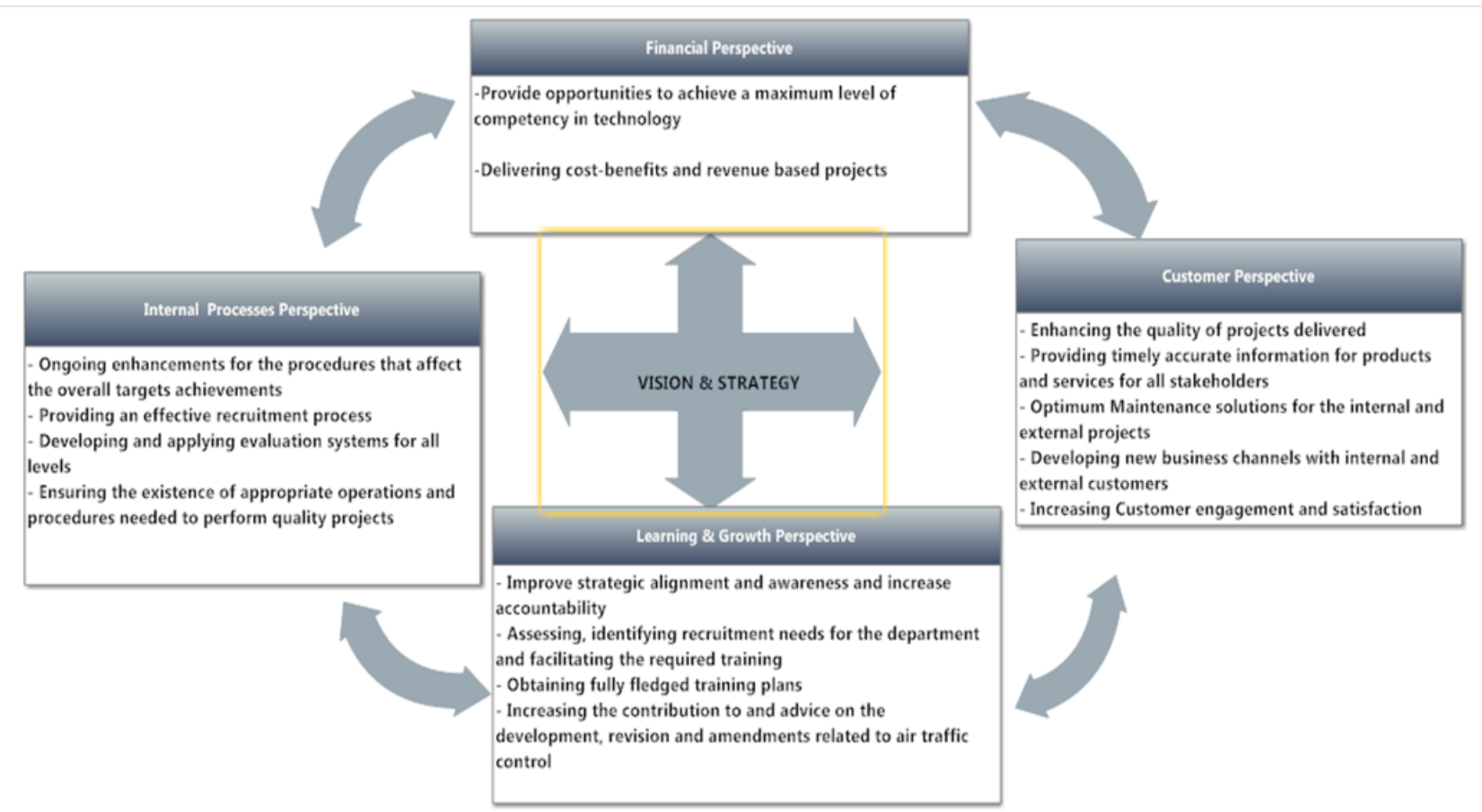

Fig 18: BSC Perspectives and Objectives

Financial Perspective

Performance \%

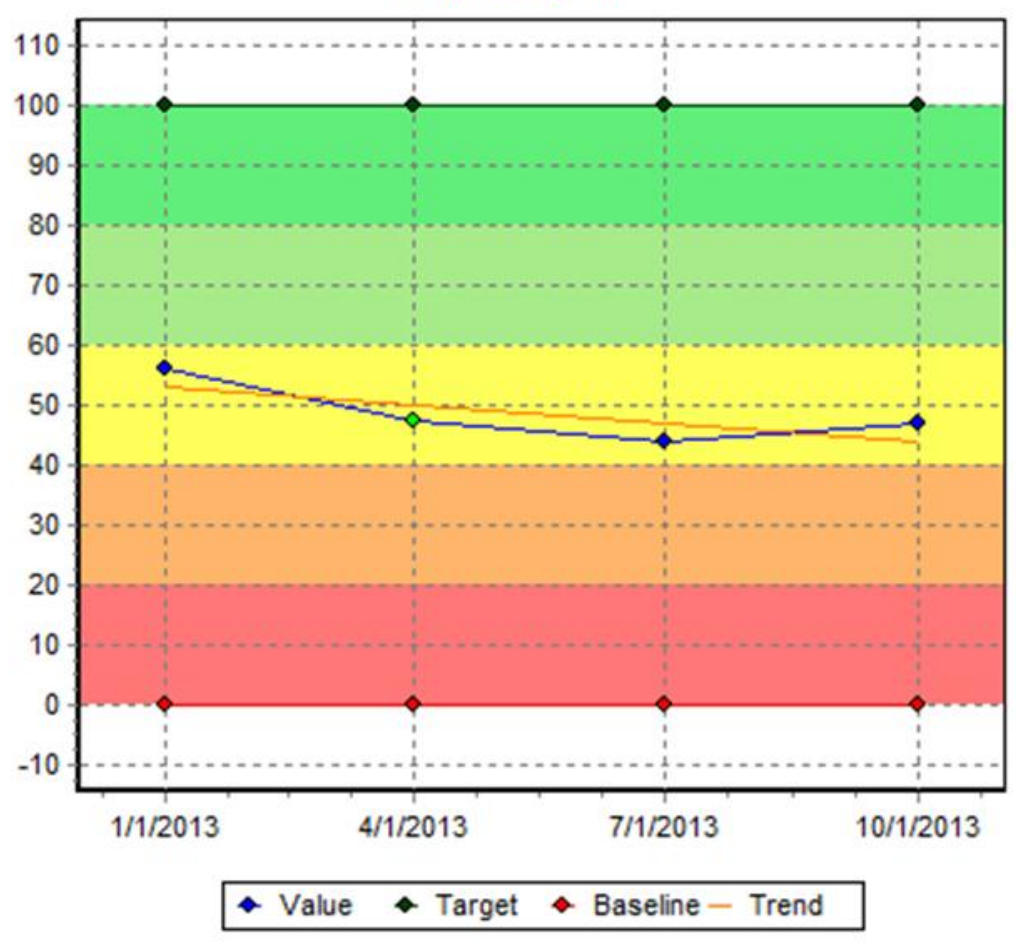

Fig 19: BSC Perspectives and Objectives 

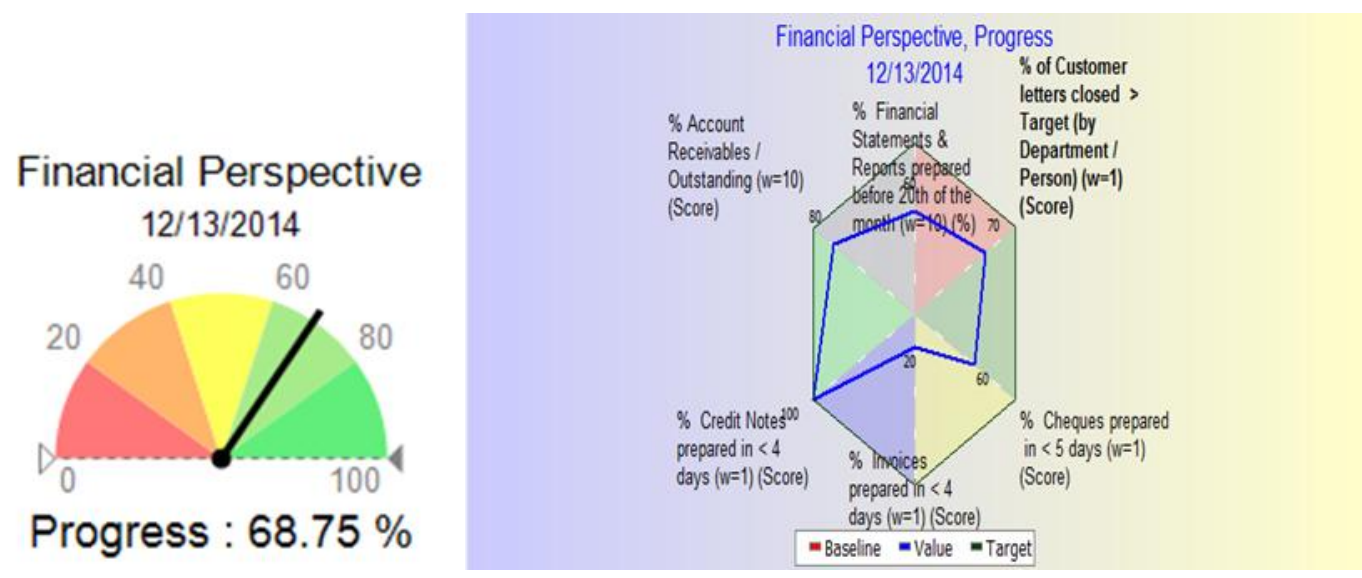

Fig 20: Financial perspective status in Dec 2014 different views

\subsection{Operational KPIs}

In order to avoid complexity and ensure that the performance measurement will take place at the operational strategic levels, operational KPIs that measure the enterprise internal operations were classified and separated from the strategic KPIs that affect the overall performance. Having the "right
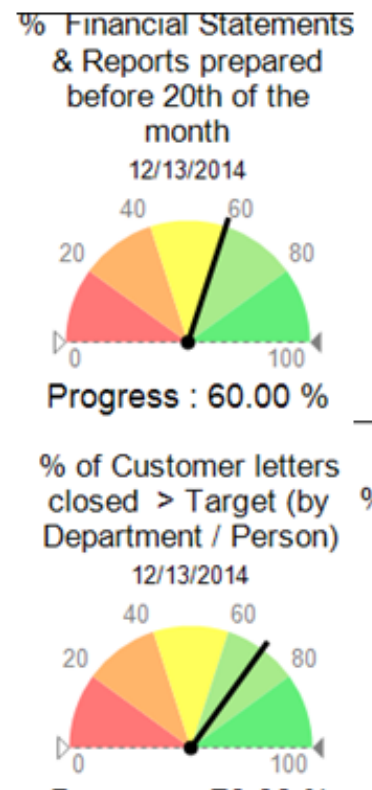

Progress : $70.00 \%$

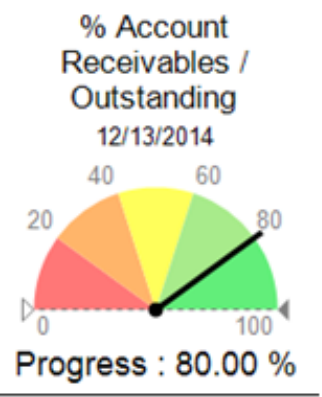

$\%$ Cheques prepared in

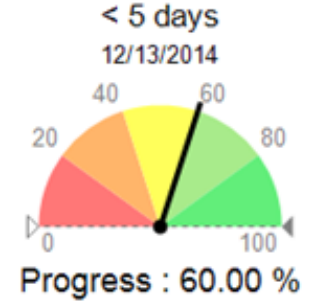

information" at the "right time" available for both individuals and departments empowers them to act upon the information related to the organizational or departmental objectives. Figure 21 shows samples of the dashboards for a set of operational KPIs that indicate the performance for both individuals and departments, such as the percentage of accounts receivable outstanding.

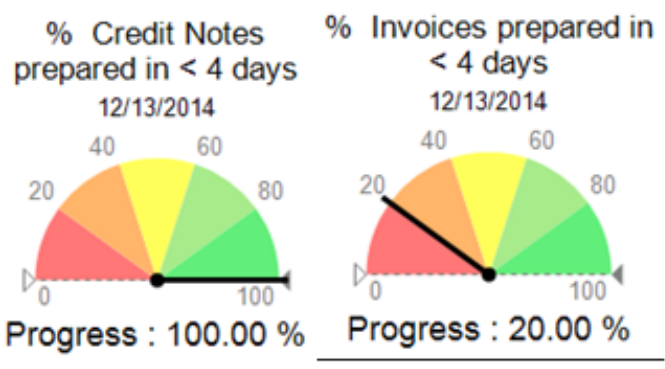

Fig 21: Operational KPIs

\subsection{Strategic KPIs}

Strategic planning and performance measurement for the organization include mission (why it exists), vision (where it wants to be in the future or how it wants to be viewed), and objectives that are the path at future vision. Specific strategies, actions, and improvement initiatives need to be incorporated into the operational activities of the organization in order to achieve the goals. (Innovation insights, 2008) In this study's case unit, the organizational KPIs that affect the overall organizational performance were defined and measured as figure 22 indicates, and for each strategic KPI a dashboard is created. 


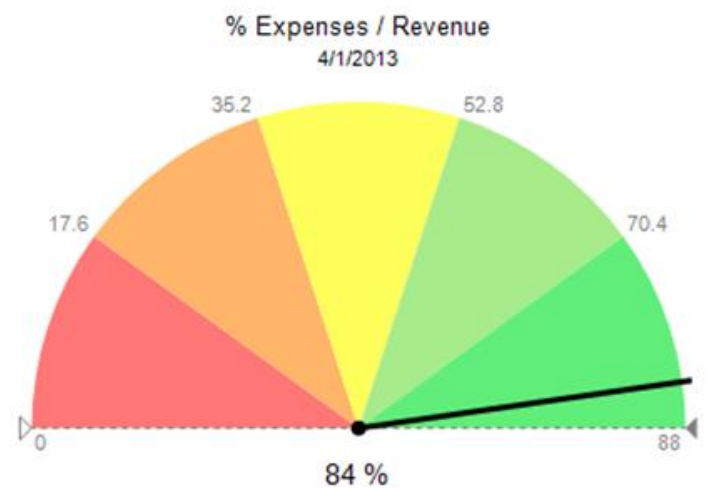

Fig 22: Strategic KPIs

Strategic KPIs are the improvement lead KPIs that reflect the organization's wide-performance dimension as well as the organization's needs. Strategic KPIs are the main objectives drivers that guide the organization for its overall direction. Examples of the strategic KPI defined for the case unit are as follow:

- $\%$ Developed Software Engineering Revenue / Costs YTD

- $\%$ Departments' Manpower Utilization

- \% Customer Training Plans Realization

- $\%$ of schedule compliance for implementation of projects tasks

- $\quad$ Quality of Work

- $\%$ of Equipment Serviceability

- $\%$ of Systems Applications Availability

- $\%$ Actual and Planned Transactions

- \% Delayed Delivery to customers to total Number of POs

- $\%$ Operating Capital

\section{SUMMARY AND CONCLUSION}

There are some important business problems that are handled when designing a strategy. The first solved problem is adopting new technologies. Enterprises are concerned when using such new technologies in their business, yet, some organizations over the world that actually design strategy to make things easier and lower the costs of their processes. Moreover, a major problem is in identifying the questions and issues an organization should address regarding the services and products of their business. Another difficulty is the effective definition of the measurements that measure the performance. The KPIs are rarely addressed on most organizations, and hardly does an organization have a road map that defines the criteria to prioritize and select the performance indicators. To summarize, when there are no defined targets, no continuous feedback on the performance is gathered, no actions are taken to improve the overall performance, it is crucial to use a performance measurement tool to solve such problems. [13].

When approaching BI solutions to support corporate strategy, it can improve the ability of performance management programs to optimize value to the organization. A business that practices BSC strategic alignment can use BI solutions for trend and predictive analyses, customer data integration, scorecards and dashboards, as well as data mining. It was noticed that the most successful organizations adopt performance management methodologies like BSC and Strategy Maps, then select metrics according to the strategic objectives set through those methodologies and as a final step, they deploy BI solutions to collect the required data in order to optimize the performance. [4]

Creating a BSC requires to address three challenges: (1) Creating a process to design, manage, report, and analyze the metrics, (2) Tackling both cultural and behavioral changes that are inherent in this approach, and (3) Confirming the honesty and quality of the technical aspects of data collection. [7] This process was applied in this case unit. Where corrective actions and management initiatives were applied to enforce the new organizational strategy and performance measurements and future work was assigned to change the corporate vision and mission and align them to the new strategic objectives.

In this case unit, the main weaknesses in applying BSC and presenting the results in a $\mathrm{BI}$ format were easily detected by analyzing the performance trends, reviewing the historical data and plotting the performance trends.

The goal from applying BSC-BI is to easily detect the performance gaps. In this case unit, performance gaps were encountered for specific KPIs. Consequently, the needed management initiatives were specified and actions plans were assigned to apply the management initiatives. Furthermore, the strategic objectives for the organization were modified to serve the organization's mission and vision.

\section{REFERENCES}

[1] S. Williams, "BI and Balanced Scorecards: Key Tools in the Performance Management Toolkit," Decision Path Consulting, 2008.

[2] M. Nemtsev, "Balanced Scorecards and PerformancePoint," senior consultant, Gen-I, 2010.

[3] S. Ghosh, S Mukherjee "Measurement of corporate performance through Balanced Scorecard: an overview," Vidyasagar University, Journal of Commerce, Vol. 11, 2006.

[4] B Paladino, N Williams "Moving strategy forward: merging the Balnanced Scorecard and Business Intelligence," Busienss Performance Management, 2008.

[5] Robert S. Kaplan, David P. Norton, "The strategy focused organization," Vol. 23, No. 1(3 parts) Part 1, 2001. 
[6] Robert S. Kaplan, David P. Norton, "The Balanced Scorecard - measure the drive performance," Harvard business review, 1992.

[7] John M. Kamensky, "Top ten list: key factors that make a Balanced Scorecard successful," IBM center for the business of government, 2005.

[8] B Kali, "Strategic performance measurement," RK Business Development LLC, 2003.

[9] Paul R. Niven R 1,"Balanced Scorecard step-by-step: maximizing performance and maintaining results," ISBN-10: 0471780499, ISBN-13: 978-0471780496, Edition: 2, 2006.

[10] C Olszak, E Ziemba, Approach to Building and Implementing Business Intelligence Systems, Interdisciplinary Journal of Information, knowledge, and Management, Volume 2, 2007.

[11] Rouse, Business Intelligence (BI), searchdatamanagement.techtarget.com, (2014).

[12] Armitage and Scholey, Using Strategy Maps to Drive Performance, ISBN 15302-193-2, 2006.

[13] Hopf, Litman and others, Guide to a Balanced Scorecard Performance Management Methodology, Procurement Executives' Association, 2002

[14] Tounsi, application and survey of business intelligence (bi) tools within the context of military decision making, Monterey, California. Naval Postgraduate School, 2012.
[15] Chandi, R., "Key Performance Indicators Measuring Performance in the Oil \& Gas EPC Industry", 2009.

[16] Wolk and others, "Building a performance measurement system- using data to accelerate social impact", Root cause Cambrige, 2009.

[17] Savkin, Integrating Balanced Scorecard and Business Intelligence (BI), bscdesigner.com, 2015

[18] BSC Institute, Building \& Implementing a Balanced Scorecard:

Nine Steps to Success, balancedscorecard.org, 2015.

[19] Queenan and Forti, Measurement as Learning: What Nonprofit CEOs, Board Members, and Philanthropists Need to Know to Keep Improving, bridgespan.org, 2011.

[20] Klipfolio, KPI-Dashboard operational metrics top 10 guidelines, klipfolio.com, 2014.

[21] Yin, R., Case study research: design and methods, 5th ed., Thousand Oaks: Sage Publications, ISBN-10: 1452242569,2013

[22] Jones,.P, Strategy Mapping for Learning Organizations, ISBN: $\quad 978-0-566-08811-7, \quad$ Short ISBN 9780566088117, 1st ed., 2011

[23] IBM Gartner, "A step-by-step approach to successful Business Intelligence", featuring research from Gartner, 2011.

[24] Quagini,L,Tonchia,S, Performance Measurement Linking Balanced Scorecard to Business Intelligence, $1^{\text {st }}$ ed., 2010 . 